\title{
Age and Time-to-Death Trajectories of Change in Indicators of Cognitive, Sensory, Physical, Health, Social, and Self-Related Functions
}

\author{
Denis Gerstorf \\ Humboldt University of Berlin and Pennsylvania State \\ University
}

Ulman Lindenberger

Max Planck Institute for Human Development, Berlin, Germany

\author{
Nilam Ram \\ Pennsylvania State University and Max Planck Institute for \\ Human Development, Berlin, Germany
}

Jacqui Smith

University of Michigan

\begin{abstract}
Mortality-related processes are known to modulate late-life change in cognitive abilities, but it is an open question whether and how precipitous declines with impending death generalize to other domains of functioning. We investigated this notion by using 13-year longitudinal data from now-deceased participants in the Berlin Aging Study $(N=439 ; 70-103$ years at first occasion; $M=87$ years). Using time metrics of chronological age and time-to-death, we compared changes in key indicators of cognitive, sensory, physical, health, social, and self-related domains. Across variables and domains, mortality models revealed steeper average rates of change than age models. However, some domain indicators were more prone to mortality-related change than others. Examining between-person differences, we found that sociodemographic characteristics (surviving to an older age at death, being a woman, lower socioeconomic status) and proxies of pathologies (comorbidities, disability, and suspected dementia) related to lower levels of late-life functioning. In contrast, little evidence was found for correlates of differential change. Our results illustrate both the pervasive nature of progressive processes leading toward death and their domain specificity. Inquiries with more closely spaced multidomain measurements are needed to identify invariant and variable aspects of the end-of-life "cascade."
\end{abstract}

Keywords: oldest-old, terminal decline, growth models, late life, mortality

Age-related, pathology-related, and mortality-related processes contribute to trajectories of functional change at the end of life (Baltes, Lindenberger, \& Staudinger, 2006; Birren \& Cunningham, 1985; Featherman \& Petersen, 1986). Empirical support for pronounced late-life deterioration with impending death has accumulated primarily in examinations of cognitive abilities (for an overview, see Bäckman \& MacDonald, 2006). Several recent studies report that well-being also shows considerable late-life declines (Berg, Hassing, Thorvadsson, \& Johansson, 2011; Diehr, Williamson, Burke, \& Psaty, 2002; Gerstorf et al., 2008, 2010; Gerstorf,
Ram, Röcke, Lindenberger, \& Smith, 2008; Mroczek \& Spiro, 2005; Palgi et al., 2010). Less is known about whether mortalityrelated declines or other progressive processes leading toward death (e.g., deteriorating health) are also present in domains other than cognition and well-being. In this article, we provide an empirical demonstration of the pervasiveness of mortality-related decline using 13-year longitudinal data from now-deceased participants in the Berlin Aging Study (BASE; $N=439 ; 70-103$ years at first occasion; $M=87$ years). First, we examined end-of-life changes in key indicators of function in six domains that broadly
This article was published Online First January 28, 2013.

Denis Gerstorf, Institute for Psychology, Humboldt University of Berlin, Berlin, Germany, and Department of Human Development and Family Studies, Pennsylvania State University; Nilam Ram, Department of Human Development and Family Studies, Pennsylvania State University, and Center for Lifespan Psychology, Max Planck Institute for Human Development, Berlin, Germany; Ulman Lindenberger, Max Planck Institute for Human Development; Jacqui Smith, Department of Psychology and Institute for Social Research, University of Michigan.

The authors gratefully acknowledge the support provided by National Institute on Aging (NIA) Grants RC1-AG035645, NIA R21-AG032379, and NIA R21-AG033109; the Max Planck Institute for Human Development, Berlin; and the Penn State Children, Youth, \& Families Consortium. The content is solely the responsibility of the authors and does not necessarily represent the official views of the funding agencies.
This article reports data from the Berlin Aging Study (BASE; www.base-berlin.mpg.de).The BASE was initiated by the late Paul B. Baltes, in collaboration with Hanfried Helmchen, psychiatry; Elisabeth Steinhagen-Thiessen, internal medicine and geriatrics; and Karl Ulrich Mayer, sociology. Financial support came from the Max Planck Society; the Free University of Berlin; the German Federal Ministry for Research and Technology (1989-1991, 13 TA 011 + 13 TA 011/A); the German Federal Ministry for Family, Senior Citizens, Women, and Youth (19921998, 314-1722-102/9 + 314-1722-102/9a); and the Berlin-Brandenburg Academy of Sciences' Research Group on Aging and Societal Development (1994-1999).

Correspondence concerning this article should be addressed to Denis Gerstorf, Humboldt University of Berlin, Institute for Psychology, Rudower Chaussee 18, 12489 Berlin, Germany. E-mail: denis.gerstorf@ hu-berlin.de 
represent central systems (cognitive, sensory, physical, health, social, and self-related functions) as age-related and as mortalityrelated processes. Second, we examined whether and how sociodemographic characteristics (age at death, gender, socioeconomic status [SES]) and proxies of pathologies (comorbidities, disability, suspected dementia) related to between-person differences in latelife functioning and change.

\section{Age-Related Change}

Normative age-related processes are often implicated as one of the major driving forces underlying developmental change (see Alwin, Hofer, \& McCammon, 2006). To index how such processes unfold, researchers describe and extract systematic within-person changes in individuals' behavior and experience as observed along a time-from-birth or chronological age time axis. Building on or using evidence of age-related deteriorations that are moderately to strongly correlated with chronological age, a sizable body of theoretical notions and empirical insights has accumulated regarding normative trajectories of age-related changes that span across cognitive, sensory, physical, health, social, and self-related functions.

In the cognitive domain, two-component life span theories of intelligence contend that age-related change trajectories of the fluid mechanics begin to decline in middle adulthood (because of underlying decrements in neurobiological functioning; Baltes et al., 2006; Cattell, 1971; Horn, 1982). These conceptual arguments are supported by a myriad of empirical reports documenting that age-normative cumulative decline in performance on speeded cognitive tasks commences relatively early in adulthood and shows moderate to strong decrements in old age (Salthouse, 2004; Schaie, 2005).

In the sensory domain, it is known that the focusing ability of the lens deteriorates with advancing age (Kline \& Scialfa, 1996). Steep age-related declines have repeatedly been documented for visual acuity and particularly close vision (Fozard \& GordonSalant, 2001). For physical functioning, theories of physiological wear and tear suggest that key parts of the body, such as cells and tissues, wear out and break down from prolonged use (for discussion, see Cristofalo, Tresini, Francis, \& Volker, 1999). Treating chronological age as a basic index of cumulative wear and tear, various measures of physical functioning are known to evince pronounced normative age-related declines (Crimmins, Hayward, \& Saito, 1996). For example, Christensen, Mackinnon, Korten, and Jorm (2001) reported from the Canberra Study of Aging that grip strength showed strong negative direct relationships with age. Likewise, self-rated health, commonly considered a multidimensional snapshot of past health experiences, current health conditions, and future health expectations (Idler, 1993), has repeatedly been found to decline with age (Sargent-Cox, Anstey, \& Luszcz, 2010).

Theories of social development assert that qualitative aspects of individuals' social life, such as feeling socially integrated and emotionally supported, are well preserved into old age (Carstensen, Isaacowitz, \& Charles, 1999; Kahn \& Antonucci, 1980). Empirical evidence supporting these conceptual arguments is ubiquitous (Antonucci, 2001). For example, Hawkley and Cacioppo (2007) concluded in their review that there are relatively few age-related increases in perceptions of loneliness across most of the adult life. Finally, theories of self-regulation and personal control and empirical reports both suggest age-related increases in the constraints people perceive on their ability to enact control over their lives (Brandtstädter \& Greve, 1994; Heckhausen \& Schulz, 1995). In the current study, we examine age-related changes in multiple indicators of cognitive, sensory, physical, health, social, and self-related functioning domains and expect that these measures evince similar trajectories of age-related change to those reported in earlier studies.

\section{Mortality-Related Change}

Late-life changes in functionality are often influenced not only by age-related factors but also by mortality-related factors associated with impending death. Notions of terminal decline suggest that mortality-related processes rise to the forefront at the end of life and are the predominant cause of the accelerated functional deteriorations that often accompany the last years and months before death (Kleemeier, 1962; Riegel \& Riegel, 1972). To index how mortality-related processes unfold, researchers describe and extract systematic within-person changes in individuals' behavior and experience along a time-to-death time axis.

The existence of precipitous, proximate-to-death declines has received strong empirical support in the cognitive domain over the past two decades (Bäckman \& MacDonald, 2006). For example, Wilson, Beckett, Bienias, Evans, and Bennett (2003) found that participants in the Religious Orders Study had lower ability levels and experienced pronounced deteriorations on a variety of cognitive abilities during the last years of life (see also Sliwinski et al., 2006; Wilson, Beck, Bienias, \& Bennett, 2007). Several recent studies have indicated that individuals' well-being also declines rapidly with impending death (Diehr et al., 2002; Mroczek \& Spiro, 2005; Palgi et al., 2010). Our own analyses of end-of-life declines in life satisfaction among now-deceased participants in the BASE revealed that, relative to age models, mortality models accounted for more variance in between-person differences in late-life change and also revealed by far steeper average rates of decline (Gerstorf, Ram, Estabrook, et al., 2008). Our objective in the current study was to examine whether and how pronounced end-of-life changes are exhibited in other domains of functioning.

The literature on mortality-related processes in the cognitive and well-being domains has identified a few candidate mortalityrelated processes, including the accumulation of neuropathologies, impairments of the central nervous systems, and the breakdown of overall system integrity. Each of these factors can be expected to have direct or indirect bearing on multiple domains. We thus contend that the effects of mortality-related processes pervade many domains of function, not just cognitive abilities and wellbeing. To illustrate, common neuropathology conditions in old age (e.g., Alzheimer's disease [AD] or Lewy bodies) as well as the deteriorating integrity of neurocognitive control systems can both be expected to seriously impede efficient functioning of higher level processes and thereby have domain-generalized rather than domain-specific effects. Similarly, if one's reserve capacity and the integrated functioning of the system become increasingly compromised, scarce resources may be allocated to basic processes of physiological functioning and maintenance rather than to mechanisms less immediately relevant for survival (e.g., self-regulation; Kotter-Grühn, Kleinspehn-Ammerlahn, Gerstorf, \& Smith, 2009). 
Extending the, thus far, limited examinations of mortalityrelated change, our study provides an initial step toward better understanding of the multidomain nature of terminal decline. To do so, we evaluate age- and mortality-related representations for describing late-life change across key indicators of central systems: cognitive, sensory, physical, health, social, and self-related functions. Our aim was to provide a quantitative description of the extent and temporal course of late-life change in multiple domains. Our general expectation was that across all domains, changes that manifest at the end-of-life are characterized not only as age-related processes but also as mortality-related processes. At the same time, we anticipate that the relative magnitude of aging- and mortalityrelated effects is not uniform across the six domains targeted, and some domains will be more prone to "attacks" from mortalityrelated processes than others (see Fozard \& Gordon-Salant, 2001; Maier \& Smith, 1999). For example, sensory functioning may exhibit strong terminal decline effects comparable to those of fluid cognitive abilities because higher order processing of visual information and broad fluid abilities both rely on the integrity of the prefrontal and medio-temporal areas of the brain (for a thorough discussion of functional and etiological accounts of cognitivesensory links, see Lindenberger \& Ghisletta, 2009). In contrast, qualitative indicators of social life may be less strongly affected by the detrimental effects of terminal decline. For example, socioemotional selectivity theory (Carstensen et al., 1999) contends that with increased limitations in future time perspective, people focus on maintaining and optimizing interactions with more intimate network members. Although chronological age has often been used as a proxy for future time perspective, one may expect that perceived limitations on one's future time perspective should align more closely with individuals' objective proximity to death (see Kotter-Gruehn, Gruehn, \& Smith, 2010). If so, people close to death may feel as socially integrated as (if not more so than) people farther away from death. Although noting that there may be some differences in the extent of decline between functional domains, our general premise is that terminal decline is a pervasive phenomenon that cuts across systems.

\section{The Role of Sociodemographic Characteristics and Proxies of Pathologies}

The risk of decline is likely regulated by both sociodemographic and biological factors. Consistent with the view of compromised biological plasticity and genetic reliability in advanced ages (Baltes \& Smith, 2003; Finch \& Kirkwood, 2000), there is evidence to suggest that the pathways into mortality for very old individuals are portended by relatively stronger declines relative to individuals dying at earlier ages. For example, Bäckman and MacDonald (2006) concluded in their review of terminal cognitive decline research that older age at death is generally associated with steeper declines. Drawing from reports of gender differentials in morbidity in old age (Moen, 1996), the years prior to death may be more dysfunctional (e.g., drawn-out decline) for women than for men. SES may also play a role in altering rates of change in core functions because people draw from accumulated reserves and resources when adjusting to late-life challenges. For example, highly educated individuals may know of, have access to, and be able to use and activate resources that help to get one's needs fulfilled for as long as possible and despite eventual difficulties and limitations (Carver, 1998; Mirowsky \& Ross, 2007; Salthouse, 1991). Individuals with access to those resources may show shallower rates of decline, whereas those without access have fewer means to deal with late-life challenges and thereby are more prone to severe and quick decline. Such resources encompass finances, knowledge and literacy, as well as selfregulation strategies. Borrowing from theories of cognitive reserve, it is also possible that such resource mechanisms even operate to compensate neurobiological degradation by using more robust and less error-prone brain networks (Stern, 2002).

Processes that accrue with or are causally linked to disease and/or disability can be assumed to play a key role in late-life change, be it as moderator or mediator of decline (Birren \& Cunningham, 1985). For example, frailty-associated factors seriously impede upon people's capability to deal with the difficulties imposed by the end of life, thereby relating to both a person's level of function and rate of decline in other domains. Such factors include, but are not limited to, physical diseases and comorbidity, disability, and various forms of clinical and preclinical stages of dementia. To begin with, chronic health conditions are established risk factors for lower levels of functioning on performance-based measures (e.g., cognitive functioning; Verhaeghen, Borchelt, \& Smith, 2003) as well as indicators of self-related functioning (e.g., perceived control; Krause \& Shaw, 2003). In a similar vein, one repercussion of the multidirectional disablement process model (Verbrugge \& Jette, 1994) is that accumulated disability reveals sizable effects on functional changes in several domains (see also Anstey, Stankov, \& Lord, 1993). Finally, there is debate in the cognitive literature as to whether terminal decline primarily reflects the progression of $\mathrm{AD}$ and particularly its preclinical stages (Bäckman \& MacDonald, 2006). Given that older adults who die with mild or moderate forms of cognitive impairment may not meet the pathologic criteria for $\mathrm{AD}$, it seems pivotal to target the role of preclinical dementia for terminal decline. In sum, the second objective in the current study was to identify factors that contribute to between-person disparities in late-life functioning and change. On the basis of notions of old-age vulnerabilities and cumulative disadvantage, we expect that older age at death, being a woman, being in lower socioeconomic strata, as well as indicators of pathologies (comorbidities, disability, and suspected dementia) all relate to lowered late-life functioning and steeper end-of-life declines.

\section{The Current Study}

Relatively little is known about what aspects of late-life functioning are prone to "attacks" from mortality-related processes and what factors contribute to end-of-life decline. We use longitudinal data from the BASE to examine the multidimensional nature of late-life change. To broadly represent central characteristics of individual functioning, we selected six domains and wellestablished indicators thereof from the measurement battery of the BASE. We pursue two sets of goals. First, we apply growth models to characterize late-life change trajectories in key indicators of cognitive, sensory, physical, health, social, and self-related functions across chronological age and time-to-death to determine whether mortality-related processes do indeed generalize across multiple domains of function. Second, we explore the role of 
sociodemographic characteristics and proxies of pathologies as correlates of mortality-related decline.

\section{Method}

We used seven-wave longitudinal data from deceased participants of the interdisciplinary BASE collected over 13 years. Detailed descriptions of the variables assessed and procedures used, as well as information about the longitudinal samples and design, can be found in Baltes and Mayer (1999) and Smith et al. (2002). Below, we provide a brief overview.

\section{Participants and Procedure}

The total BASE sample at Time 1 (T1) comprised 516 participants who completed an intensive assessment protocol. The sample was stratified by gender and age, with 43 men and 43 women in each of six different age brackets $(70-74,75-79$, 80-84, 85-89, 90-94, and 95+ years; born between 1887 and 1922; age: $M=84.92$ years, $S D=8.66$, range $=70-103$ ). Over the next 13 years, participants who were alive and could be located were asked to complete questionnaires and tests at approximately 2-year intervals. With the exception of the geriatric medicine evaluations, all testing took place at the participant's place of residence (i.e., private household or institution) and was carried out in individual face-to-face sessions by trained research assistants and medical personnel. Sessions required an average of $90 \mathrm{~min}$ and, when necessary, were split into shorter units of assessment.

Although the original 516 sample was positively selected, the amount of selection bias in terms of mean levels and (co)variance structure was relatively small. Information about mortality status and date of death for deceased participants has been updated regularly from the Berlin city registry since study inception in 1990. Our information on death makes use of data from a March 2007 update, when, of the 516 sample, 439 participants were known to have died, 57 were still alive, and mortality information was missing for 20 participants who had moved out of the Berlin area. As can be expected from a study of old and very old individuals, sample attrition over time was sizable. The number of individuals participating at each wave was as follows: At baseline in 1990-1993 (T1): $N=439$, in 1993-1994 (Time 2 [T2]) $n=$ 292, 1995-1996 (Time 3 [T3]) $n=183,1997-1998$ (Time 4 [T4]) $n=111,2000$ (Time 5 [T5]) $n=48,2004-2005$ (Time 6 [T6]) $n=13$, and 2005 (Time 7 [T7]) $n=6$. T2 took place 1.93 years $(S D=0.69)$, T3 3.75 years $(S D=0.64), \mathrm{T} 45.48$ years $(S D=$ $0.76)$, T5 8.89 years $(S D=0.83)$, T6 12.62 years $(S D=0.85)$, and $\mathrm{T} 713.13$ years $(S D=0.87)$ after $\mathrm{T} 1$, respectively. Of the participants, 292 , or $67 \%$ contributed two or more data points and thus lend themselves to the examination of within-person change $(M$ observation period $=2.25$ years, $S D=2.63$; range $=0-14$ years). However, extensive longitudinal data were available from only a few participants (one wave of data: $n=147$; two waves: $n=109$; three waves: $n=72$; four waves: $n=63$; five waves: $n=35$; six waves: $n=7$; seven waves: $n=6$ ). We examined the longitudinal selectivity of the BASE sample using an effect size metric that indicates the degree to which individuals who survived and participated longitudinally differed from the 516 sample in BASE at T1 (see Lindenberger, Singer, \& Baltes, 2002). For example, based on the 111 deceased participants who provided data for four or more occasions, we found that better performance on the Digit Letter at T1 (0.61 SD units, with $S D$ referring to that of the 516 sample), on the tests of close vision $(0.48 S D)$ and grip strength $(0.40 S D)$, better self-rated health $(0.16 S D)$, lower emotional loneliness $(-0.21 S D)$ and more perceived control $(0.25 S D)$, younger age $(-0.78 S D)$, higher SES $(0.17 S D)$, and fewer medical diagnoses $(-0.25 S D)$ were all associated with subsequently lower mortality and higher participation rates among survivors. Effects of sample selectivity were primarily due to mortality (e.g., Digit Letter: $72 \%$ of the total effect of $.61 S D$ units) rather than dropout for other reasons, increasing the viability of the deceased sample for examination of mortality-related change. ${ }^{1}$ We note that the attrition of the sample is a beneficial aspect of studying mortalityrelated processes. By definition, mortality-related change can only be extracted retrospectively from longitudinal data from individuals with known death dates. Finally, the average age at death for the 439 participants used in our analyses was 91.67 years $(S D=$ 7.04; range $=73-106$ years). Participants died an average of 5.37 years $(S D=3.86$; range $=90$ days -16 years $)$ after their initial assessment $(\mathrm{T} 1)$ and 2.40 years $(S D=2.32$; range $=5$ days -13 years) after their last assessment.

\section{Measures}

Working within the constraints of the measures included in the longitudinal assessment battery of the BASE, we selected one reliable and well-established indicator variable for each domain under study. Acknowledging the heterogeneity of these domains, we replicated the analysis and used another indicator (that was available at multiple measurement occasions) for each domain. These results are reported in the Appendix and are substantively identical to those presented in the main text.

Outcomes. As a central index of cognitive functioning, we used individuals' repeated performance on the Digit Letter test. The Digit Letter test closely resembles the Digit Symbol Substitution test of the Wechsler Adult Intelligence Scale (Wechsler, 1982). Throughout the duration of the test (3 min), a template with nine digit-letter pairings was presented to the participants. Participants were shown a series of digits (six per page) and were required to name the corresponding letter pair, as fast as possible. To index sensory functioning, we used a performance-based measure of close visual acuity. Close visual acuity was measured with

\footnotetext{
${ }^{1}$ As one would expect, relative to those who had died, the 77 participants who survived $(n=58)$ or had missing mortality information $(n=19)$ showed better performance on the Digit Letter at T1 $(M=55.23, S D=$ 8.69 vs. $M=49.01, S D=9.93), F(1,474)=26.04$; on the tests of close vision $(M=54.81, S D=8.38$ vs. $M=49.15, S D=10.03), F(1,510)=$ 21.79; and grip strength $(M=53.28, S D=10.37$ vs. $M=49.42, S D=$ 9.83), $F(1,508)=9.96)$; they reported better self-rated health $(M=52.53$ $S D=9.31$ vs. $M=50.00, S D=10.00), F(1,514)=4.28$; lower emotional loneliness $(M=47.12, S D=9.24$ vs. $M=50.51, S D=10.05)$, $F(1,514)=7.62$; and more perceived control $(M=53.25, S D=8.10 \mathrm{vs}$ $M=49.43, S D=10.20), F(1,513)=9.74$; and were younger age $(M=$ $77.02, S D=6.15$ vs. $M=86.30, S D=8.29), F(1,514)=87.98$, and suffered from fewer medically diagnosed illnesses $(M=44.85, S D=7.79$ vs. $M=50.90, S D=10.08), F(1,514)=25.16$, all $p$ s $<.05$, whereas no differences were found in SES $(p>.10)$. In sum, as expected given their alive status, these individuals may have been at points earlier on in the terminal decline trajectory.
} 
standard optometric procedures as the average performance across right and left eyes when reading a standard Snellen chart presented at reading distance. Following previous work in the BASE, we used the best scores with or without corrective lenses because corrective devices should filter out, to a certain degree, peripheral variance (e.g., variance due to individual differences in the refractory properties of the lenses), thereby allowing for a more direct assessment of the portion of sensory loss that is central-neuronal in nature (see Lindenberger \& Baltes, 1997). As an indicator of physical functioning, we focused on upper-body function using handgrip strength. Grip strength was assessed with standardized dynamometry as the maximum force applied to a hand dynamometer across six trials, three per hand. The force exerted was measured in kilograms. As a central indicator of health, we used self-ratings of health. We computed a unit-weight composite of answers to two questions asking participants to rate their current physical health and their current mental health, using a 5-point Likert-scale ranging from 1 (poor to 5 (very good). To index social functioning, we focused on reports of loneliness. More specifically, four items selected from the UCLA Loneliness Scale (Russell, Cutrona, Rose, \& Yurko, 1984) were used to assess aspects of emotional loneliness, including feelings of isolation, being alone, and being secluded from contact with others. Participants were read each item aloud and asked to indicate how well items described them using a 5-point Likert-scale ranging from 1 (does not apply to me at all) to 5 (applies very well to me). As a central indicator of self-related function, we selected perceived control as measured using a unit-weighted composite of seven items; three items assessing personal control over desirable outcomes (e.g., "I can make sure that good things come my way"), and four items assessing perceived others' control over desirable and undesirable outcomes (e.g., "The good things in my life are determined by other people"). Participants were asked to indicate the extent to which they agreed with each of the items, using a 5-point Likertscale ranging from 1 (does not apply to me at all) to 5 (applies very well to me). Responses to items assessing perceived others' control were reverse coded so that higher scores reflect greater perceptions of control. Note that (in contrast to all other measures used here) data on perceived control were not available at $\mathrm{T} 2$.

Correlates. We examined age at death, gender, SES, comorbidities, disability, and suspected dementia as correlates of late-life functionality and change. SES was measured using a unit-weighted composite of three measures: (a) equivalent income, defined as the net household income weighted by the number of people sharing the household; (b) occupational prestige, based on a standard rating scale for Germany; and (c) number of years of education. Extent of comorbidities was measured as the number of physicianobserved diagnoses (determined in clinical examinations supported by additional blood and saliva laboratory assessments) of moderate to severe chronic illnesses (according to the International Classification of Diseases-9; for details, see Steinhagen-Thiessen \& Borchelt, 1999). Disability was recorded as whether or not a participant reported needing assistance in carrying out basic activities of daily living (getting up, getting dressed, going to the toilet, bathing, eating) at any point during the course of the study. Finally, suspected dementia was indexed by age cohort-specific cutoffs on the Short Mini-Mental State Examination (Klein et al., 1985; range $=0-18$ points; $70-84$ years: $<12$ points; $85+$ years: $<11$ points) at any point during the course of the study. Independent clinical diagnoses of dementia in the BASE at T1 and T3 indicated sufficient specificity and sensitivity of these cutoffs.

\section{Data Preparation and Data Analysis}

All measures were standardized to a $T$ metric $(M=50 ; S D=$ 10) using the T1 BASE sample as the reference $(N=516)$. This transformation provided a common metric for comparison across domains. Individuals' chronological age was noted for each available assessment as the number of years since birth. Time-to-death was noted for each available assessment as the number of years remaining in that individuals' life. Missing data were accommodated using full information maximum likelihood under the usual missing at random assumptions underlying accelerated longitudinal designs (R. J. A. Little \& Rubin, 1987).

To illustrate the layout of the data, descriptive statistics for one of the domain indicators (the Digit Letter test) over age and time-to-death are reported in Table 1 . It can be seen that average levels of cognitive functioning decline with both age and closeness to death (e.g., $M=57.29$ at 10 years prior to death, $M=44.90$ in the year of death). It may also be noted from Table 1 that observations were spread relatively equally across the three age decades (70s: $n=255,80 \mathrm{~s}: n=435$; 90+s: $n=299$ ), but were largely obtained in the last 5 years of life (e.g., $58 \%$, or $n=569$ ). The correlation between age and time-to-death was of moderate size ( $r=.47, p<.001)$, suggesting that older individuals were closer to death (i.e., higher ages are closer to zero on the time-to-death metric).

To examine our research questions, we first fitted separate growth curve models for each indicator over chronological age and effectively modeled between-person differences in how individuals' cognitive, sensory, physical, health, social, and self-related functions changed from age 70 to age 100 years. We proceeded in an analogous fashion and fitted separate growth curve models for the six indicators over time-to-death, modeling change as a function of impending mortality (i.e., up to 15 years prior to death). These models were specified as,

$$
\text { function }_{t i}=\beta_{0 i}+\beta_{1 i}\left(\text { time }_{t i}\right)+\beta_{2 i}\left(\text { time }_{t i}^{2}\right)+e_{t i},
$$

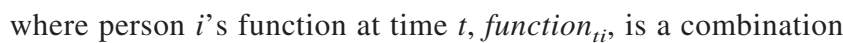
of an individual-specific intercept parameter, $\beta_{O i}$, individualspecific linear and quadratic slope parameters, $\beta_{1 i}$ and $\beta_{2 i}$, that capture the linear and quadratic rates of change per year over the selected time metric (age or time-to-death) and residual error, $e_{t i}$. Following standard multilevel/latent growth modeling procedures (Ram \& Grimm, 2007; Singer \& Willett, 2003), individual-specific intercepts, $\beta_{O i}$, and slopes, $\beta_{I i}$ and $\beta_{2 i}$, (from the Level 1 model given in Equation 1) were modeled as:

$$
\begin{aligned}
& \beta_{0 i}=\gamma_{00}+\gamma_{01} \text { Tltime }_{i}+u_{0 i,}, \\
& \beta_{1 i}=\gamma_{10}+\gamma_{11} \text { Tltime }_{i}+u_{1 i,}, \text { and } \\
& \beta_{2 i}=\gamma_{20}
\end{aligned}
$$

(i.e., Level 2 model), where $\gamma_{o o}, \gamma_{10}$, and $\gamma_{20}$ are sample means, and $u_{O i}$ and $u_{1 i}$ are individual deviations from those means that are assumed to be multivariate normally distributed, correlated with each other, and uncorrelated with the residual errors, $e_{t i}$. Deviations for the quadratic slope, $u_{2 i}$, were examined, but 
Table 1

Descriptive Statistics for the Cognitive Indicator (Digit Letter) Over Age and Time-to-Death

\begin{tabular}{|c|c|c|c|c|c|c|c|c|}
\hline & \multicolumn{4}{|c|}{ Chronological age } & \multicolumn{4}{|c|}{ Time-to-death } \\
\hline & Age & $n$ & Estimate & $S E$ & $\begin{array}{l}\text { Years before } \\
\text { death }\end{array}$ & $n$ & Estimate & $S E$ \\
\hline Between-person variance & & & 53.42 & 7.93 & & & 5.49 & 0.61 \\
\hline Within-person variance & & & 7.93 & 0.46 & & & 7.53 & 0.42 \\
\hline \multirow[t]{38}{*}{ ICC } & & & .87 & & & & .42 & \\
\hline & & & $M$ & $S D$ & & & $M$ & $S D$ \\
\hline & 70 & 5 & 51.05 & 7.80 & 16 & 2 & 51.46 & 8.69 \\
\hline & 71 & 9 & 58.55 & 6.80 & 15 & 11 & 59.96 & 6.35 \\
\hline & 72 & 15 & 58.26 & 7.14 & 14 & 14 & 55.04 & 9.26 \\
\hline & 73 & 13 & 54.69 & 10.43 & 13 & 24 & 55.08 & 9.41 \\
\hline & 74 & 27 & 56.12 & 7.85 & 12 & 27 & 57.63 & 7.95 \\
\hline & 75 & 31 & 55.98 & 7.49 & 11 & 27 & 56.83 & 6.55 \\
\hline & 76 & 32 & 56.56 & 8.24 & 10 & 41 & 57.29 & 6.85 \\
\hline & 77 & 25 & 55.23 & 8.68 & 9 & 42 & 54.43 & 9.36 \\
\hline & 78 & 38 & 54.65 & 8.32 & 8 & 50 & 53.32 & 8.84 \\
\hline & 79 & 41 & 54.45 & 8.16 & 7 & 63 & 53.72 & 8.56 \\
\hline & 80 & 46 & 52.61 & 9.26 & 6 & 72 & 51.20 & 10.65 \\
\hline & 81 & 39 & 52.83 & 8.62 & 5 & 93 & 50.44 & 9.32 \\
\hline & 82 & 45 & 53.54 & 9.34 & 4 & 114 & 48.22 & 9.44 \\
\hline & 83 & 41 & 51.60 & 7.72 & 3 & 116 & 47.41 & 8.96 \\
\hline & 84 & 40 & 52.92 & 8.90 & 2 & 129 & 45.98 & 10.52 \\
\hline & 85 & 57 & 52.25 & 9.63 & 1 & 124 & 45.90 & 9.96 \\
\hline & 86 & 45 & 48.42 & 8.67 & 0 & 40 & 44.92 & 10.29 \\
\hline & 87 & 42 & 49.44 & 11.15 & & & & \\
\hline & 88 & 46 & 49.39 & 9.95 & & & & \\
\hline & 89 & 37 & 48.42 & 9.99 & & & & \\
\hline & 90 & 32 & 48.64 & 8.66 & & & & \\
\hline & 91 & 35 & 47.09 & 9.71 & & & & \\
\hline & 92 & 31 & 46.06 & 9.78 & & & & \\
\hline & 93 & 29 & 46.19 & 9.19 & & & & \\
\hline & 94 & 19 & 41.52 & 9.14 & & & & \\
\hline & 95 & 37 & 42.24 & 9.69 & & & & \\
\hline & 96 & 29 & 43.02 & 8.51 & & & & \\
\hline & 97 & 35 & 43.65 & 9.11 & & & & \\
\hline & 98 & 18 & 42.39 & 8.32 & & & & \\
\hline & 99 & 19 & 38.51 & 7.98 & & & & \\
\hline & 100 & 14 & 43.02 & 9.03 & & & & \\
\hline & 101 & 10 & 41.87 & 9.05 & & & & \\
\hline & 102 & 4 & 39.09 & 16.12 & & & & \\
\hline & 103 & 1 & 53.51 & - & & & & \\
\hline & 104 & 1 & 24.84 & - & & & & \\
\hline & 105 & 1 & 39.51 & - & & & & \\
\hline
\end{tabular}

Note. $\quad N=404$ who provided 989 observations. T-scores standardized to cross-sectional BASE sample at Time $1(n=516, M=50, S D=10)$. ICC $=$ intraclass correlation. Dashes indicate that variance cannot be computed for $n=1$.

there were no significant between-person differences, and thus they were not included in the final models. Similarly, cubic terms were also included and tested, but were not significantly different from zero for any of the domain indicators tested. Between-person versions of the time metric, Tltime , $_{\text {, were }}$ included at Level 2 to accommodate nonconvergence between within-person change and between-person differences (e.g., cohort effects: Participants who are alive and well to begin a scientific study at age 85 may not necessarily be representative of those who began the study at an earlier age and who may or may not have participated in the study until reaching age 85; see, e.g., Sliwinski, Hoffman, \& Hofer, 2010). For example, in the age-based model, we added chronological age at T1 (centered at 85 years) as a predictor of person-specific intercepts and linear age-related rates of change at Level 2. In analogue, time-to-death (centered at 2 years prior to death) at T1 was included at Level 2 as a predictor of intercept and linear time-to-death-related change.

To examine whether and how the between-person variance in individuals' change trajectories over time-to-death was associated with sociodemographic characteristics and proxies for pathologies, the time-to-death model was expanded by adding age at death, gender, SES, comorbidities, disability, and suspected dementia as predictors at the between-person level (Level 2). These variables were effect coded/centered so that the regression parameters indicated the average trajectory (across all individuals) and the extent of differences associated with a particular variable (rather than for a particular group). Negative parameters indicate differences at the "disadvantage" of 
individuals surviving to an older age, women, those with lower SES, those with more comorbidities, disabled participants, and those with suspected dementia. The expanded model took the form,

$$
\begin{aligned}
\beta_{0 i}=\gamma_{00} & +\gamma_{01}\left(\text { age of death }_{i}\right)+\gamma_{02}\left(\mathrm{SES}_{i}\right)+\gamma_{03}\left(\text { gender }_{i}\right) \\
& +\gamma_{04}\left(\text { comorbidities }_{i}\right)+\gamma_{05}\left(\text { disability }_{i}\right) \\
& +\gamma_{06}\left(\text { suspected dementia }_{i}\right)+u_{0 i},
\end{aligned}
$$

and

$$
\begin{aligned}
& \beta_{1 i}=\gamma_{10}+\gamma_{11}(\text { age at death } i)+\gamma_{12}\left(\operatorname{SES}_{i}\right)+\gamma_{13}\left(\text { gender }_{i}\right) \\
& +\gamma_{14}\left(\text { comorbidities }_{i}\right)+\gamma_{15}\left(\text { disability }_{i}\right) \\
& +\gamma_{16}\left(\text { suspected dementia }_{i}\right)+u_{1 \mathrm{i}} \text {. }
\end{aligned}
$$

For self-rated health, emotional loneliness, and perceived control, main effects on the linear change trajectory were tested in absence of the random effects. We also included main effects of each correlate on the curvature of the average change trajectories (i.e., quadratic change). Because five of the six correlates did not reveal reliable differences on any domain indicator in those analyses, we only report results for the single correlate that evinced significant differences in the quadratic term of change.

All models were fit to the data using SAS (Proc Mixed; R. C. Littell, Miliken, Stoup, \& Wolfinger, 1996). The time variable was centered at age 85 years in the age-related change models, and at 2 years prior to death in the mortality-related change models. We note that the correlates included in our models represent attritioninformative variables, which helped to accommodate longitudinal selectivity under the assumption that incomplete data were missing at random (i.e., missingness may have been related to these variables; McArdle, 1994).

\section{Results}

All six domain indicators exhibited a sizable proportion of within-person variation over time, ranging between .21 for the Digit Letter test and .52 for close vision. Because age and timeto-death models differ in the between-persons portion of the model, we also examined the proportion of between-person differences in levels and rates of change that are accounted for by cross-sectional age differences and cross-sectional time-to-death differences. To do so, we evaluated the relative amount of variance that heterogeneity in age or time-to-death accounted for (see the intraclass correlations in Table 1). Of particular note was that between-person variance in age (53.42) was almost 10 times larger than variance in time-to-death (5.49). This reflects the use of typical sample selection strategies that attempt to maximize age heterogeneity (here, across old age) while implicitly reducing heterogeneity in time-to-death.

\section{Age- and Mortality-Related Change Trajectories in Multiple Domains of Functioning}

Table 2 summarizes the fixed effects (mean estimates) and random effects (variance estimates) of both age and time-to-death growth curve models for each of the six domain indicators. For a considerable number of (primarily age-related) models, we found significant associations between $\mathrm{T} 1$ and the time metric used (age or time-to-death), indicating that the cross-sectional age/time-todeath differences observed are, on average, not equivalent to the longitudinal age/time-to-death changes observed (i.e., presence of age or time-to-death-based selection). For most variables, we found evidence of positive selection (e.g., Digit Letter $=0.19$ and 0.04 for intercepts and slopes, respectively), but for a few there was some negative selection (e.g., grip gtrength $=-0.23$ and 0.03 ). Given the prevalence of these effects, they were retained through evaluation of the time metrics.

To describe late-life change over age and time-to-death, we ran models with each time metric and evaluated the additional amount of explained variance when either age or time-to-death was added to the within-person (Level 1) portion of the model. Following Snijders and Bosker (1999), this is formally conceptualized as the proportional reduction of prediction error (i.e., pseudo $R^{2}$ ). ${ }^{2}$ For the objective, performance-based variables of Digit Letter, close vision, and grip strength, the relative proportion of variance explained tended to be higher for the time-to-death metric relative to the age metric. For the Digit Letter, for example, the change in pseudo- $R^{2}$ was 0.490 for the time-to-death metric as compared with 0.390 for the age metric. For self-report variables of self-rated health, loneliness, and perceived control, the amount of explained variance was more even, suggesting that both age- and mortalityrelated processes contribute to between-person differences in latelife change in these domains. For example, pseudo- $R^{2}$ for loneliness was 0.133 for the time-to-death metric as compared with 0.125 for the age metric.

To examine the total variance explained by these models, we also estimated additional models over time-in-study, with age or time-to-death at T1 as a Level 2 predictor. The squared correlation between the actual outcomes and the outcomes predicted by the fixed effects in these models revealed for the Digit Letter, for example, few differences ( $r=.44$ over age vs. $r=.40$ over time-to-death). Interpreting this total variance explained in the context of our earlier findings of larger between-person differences in age than in time-to-death suggests that it takes some 50 years of age variance to describe a bit more about late-life change in a central indicator of cognitive abilities than what 5 years of timeto-death variance describes. The corresponding figures for the other domain indicators revealed a similar picture (close vision over age: $r=.45$; close vision over time-to-death: $r=.38$; grip strength over age: $r=.48$; grip strength over time-to-death: $r=$ .24 ; self-rated health over age: $r=.13$; self-rated health over time-to-death: $r=.19$; loneliness over age: $r=.29$; loneliness over time-to-death: $r=.19$; perceived control over age: $r=.27$; perceived control over time-to-death: $r=.20$ ).

In the next step of the analysis, we considered average rates of late-life change. The pattern is highly consistent across the six measures targeted, suggesting that typical rates of change associ-

\footnotetext{
${ }^{2}$ As recommended by Snijders and Bosker (1999, pp. 99-105), we calculated the explained proportion of within-person variance as $\Delta$ pseudo- $R^{2}=1-\left(\sigma_{\mathrm{e}(\mathrm{c})}^{2} / \sigma_{\mathrm{e}(\mathrm{u})}^{2}\right),(4)$ where $\sigma_{\mathrm{e}(\mathrm{u})}^{2}$ is the residual within-person variance obtained from an unconditional or intercept-only model and $\sigma_{\mathrm{e}(\mathrm{c})}^{2}$ is the parallel term from the conditional model that includes the time variable, age or time-to-death. The residual within-person variances of the unconditional model were as follows: Digit Letter, $\sigma_{\mathrm{e}(\mathrm{u})}^{2}=22.20$; close vision, $\sigma_{\mathrm{e}(\mathrm{u})}^{2}=43.98$; grip strength, $\sigma_{\mathrm{e}(\mathrm{u})}^{2}=20.56$; self-rated health, $\sigma_{\mathrm{e}(\mathrm{u})}^{2}=$ 49.70; emotional loneliness, $\sigma_{\mathrm{e}(\mathrm{u})}^{2}=31.40$; and perceived control, $\sigma_{\mathrm{e}(\mathrm{u})}^{2}=$ 39.25 .
} 


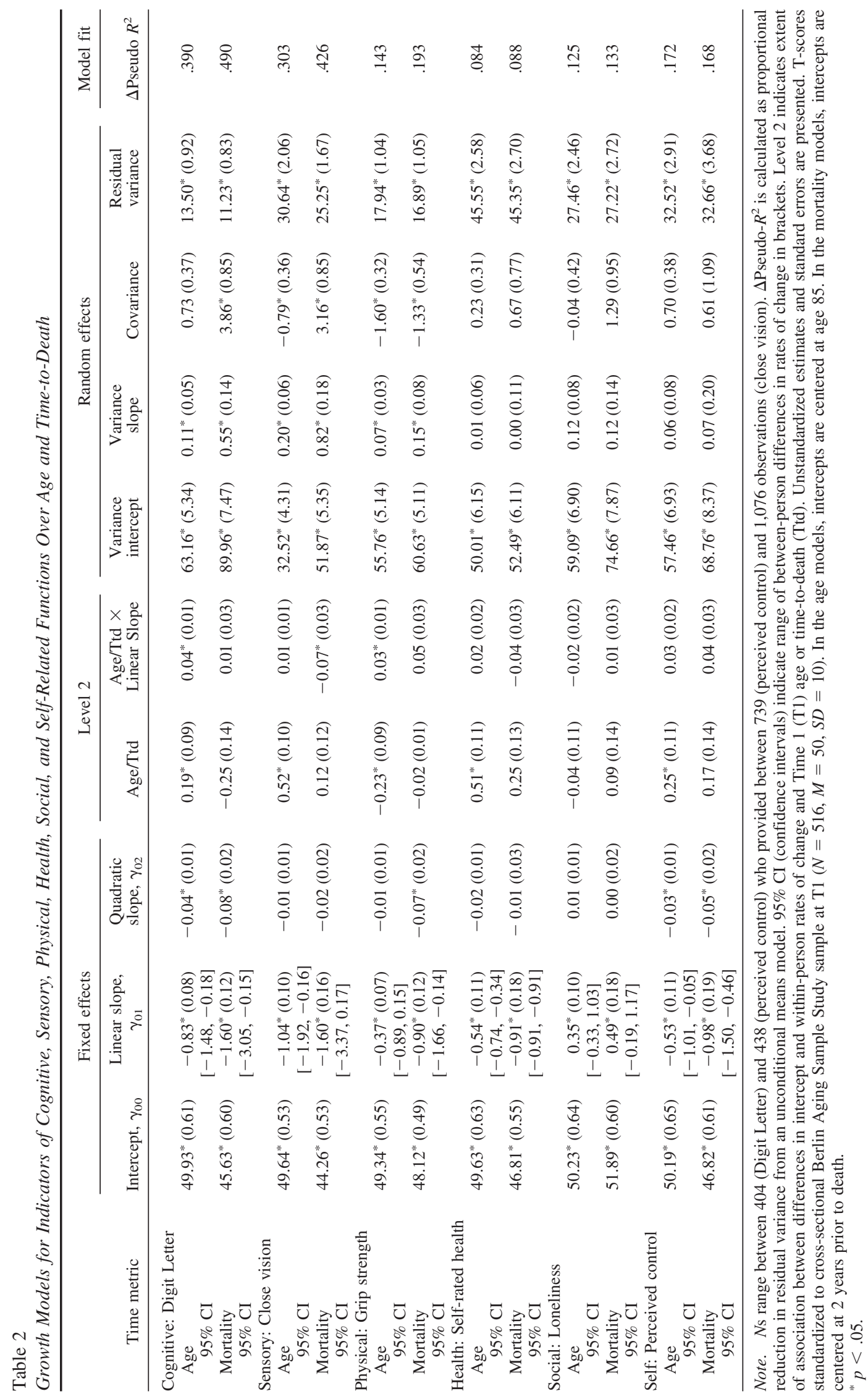


ated with impending death were steeper than those related to chronological age. For example, the linear component of mortality-related decline for the Digit Letter amounted to more than 1.5 standard deviations per 10 years (e.g., $\gamma_{10}=-1.60$ for time-to-death vs. $\gamma_{10}=-0.83$ for age) with some concave curvature $\left(\gamma_{20}=-0.08\right.$ vs. $\gamma_{20}=-0.04$ for age $)$. In relative terms, the shallowest rates of late-life change were evinced by emotional loneliness, but even for this dimension, the average mortalityrelated increases (0.49 T-score units per year) were more pronounced than the average age-related increases $(0.35 \mathrm{~T}$-score units per year). To illustrate, Figures 1 and 2 contrast the typical agerelated and mortality-related change trajectories for the six indicators of cognitive, sensory, physical, health, social, and self-related functions. Across domains, mortality-related models revealed steeper average rates of change than age-related models by a factor of between 1.4 (loneliness) and 2.5 (close vision). As well, the extent of discernible between-person differences in rates of change differed between domain indicators (see Table 2).

\section{The Role of Sociodemographic Characteristics and Proxies of Pathologies}

Results from models examining how sociodemographic characteristics and proxies of pathologies are associated with betweenperson differences in late-life functioning and change are reported in Table 3. Our findings revealed that surviving to an older age, being a woman, and lower SES, as well as comorbidities, disability, and suspected dementia were indeed associated with lower late-life levels of functioning, whereas we found relatively few correlates of late-life changes. More specifically, age at death and SES both related to level differences on four or more domain indicators at 2 years before death. For example, surviving to an older age at death was associated with lower levels of Digit Letter performance $\left(\gamma_{O I}=-0.45\right)$, visual acuity $\left(\gamma_{O I}=-0.34\right)$, and grip strength $\left(\gamma_{01}=-0.39\right)$, as well as more emotional loneliness $\left(\gamma_{O 1}=0.22\right)$ and lower perceived control $\left(\gamma_{O I}=-0.20\right)$. In addition, persons who died at an older age were found to show steeper declines on the Digit Letter $\left(\gamma_{11}=-0.03\right)$, whereas older age related to less pronounced decline on grip strength $\left(\gamma_{11}=\right.$ 0.02 ), and higher SES was related to a somewhat steeper decline in visual acuity $\left(\gamma_{12}=-0.02\right)$. For gender, we found that women had lower grip strength $\left(\gamma_{03}=-9.72\right)$, and reported lower health $\left(\gamma_{03}=-1.87\right)$, more loneliness $\left(\gamma_{03}=1.65\right)$, and lower perceived control $\left(\gamma_{03}=-2.74\right)$ than men. Women also showed slightly less decline in grip strength with approaching death $\left(\gamma_{13}=0.49\right)$, perhaps reflecting some floor effects.

For comorbidities, our results indicate that participants with more moderate to severe chronic illnesses had lower grip strength $\left(\gamma_{04}=-0.09\right)$, lower self-reported health $\left(\gamma_{04}=-0.09\right)$, and reported higher levels of loneliness $\left(\gamma_{o 3}=0.11\right)$. Greater number of physical diseases was also related to a steeper decline in grip strength $\left(\gamma_{14}=-0.01\right)$. The presence of disability was associated with lower performance on the Digit Letter $\left(\gamma_{05}=-2.98\right)$, grip strength $\left(\gamma_{05}=-1.66\right)$, and reports of lower perceived control $\left(\gamma_{05}=-4.46\right)$. Disabled participants also declined more strongly on the Digit Letter $\left(\gamma_{15}=-0.32\right)$ and grip strength $\left(\gamma_{15}=-0.29\right)$. Finally, participants suffering from suspected dementia performed lower on the Digit Letter $\left(\gamma_{o \sigma}=-6.68\right)$ and the grip strength tests $\left(\gamma_{o 6}=-0.85\right)$ and, as to be expected, showed steeper linear and quadratic rates of change on the Digit Letter test $\left(\gamma_{16}=-0.59\right.$ and $\left.\gamma_{17}=-0.06\right)$. Interestingly, suspected dementia also related to shallower declines on self-rated health $\left(\gamma_{16}=0.37\right)$ and perceived control $\left(\gamma_{16}=0.57\right)$. The reduction in unexplained variance in intercepts and slopes was used to quantify the contribution of the predictors along an effect size-type metric. As can be seen in Table 3 , the correlates accounted for substantial amounts of variance (e.g., Digit Letter intercept variance reduction $=48 \%$; slope $=$ $38 \%$ ). Overall, our results indicate that sociodemographic characteristics and proxies of pathologies were independently related to late-life levels of functioning, but were not independently related to differential rates of change.

\section{Discussion}

Our objective was to examine the systemic nature of late-life change. To do so, we applied growth models to 13-year longitudinal data from 439 now-deceased participants in the BASE to examine age-related and mortality-related change in cognitive, sensory, physical, health, social, and self-related functions. Results revealed that late-life changes in performance-based variables are primarily driven by mortality-related processes, whereas changes in self-report variables are perhaps driven more evenly by both age- and mortality-related processes. Relative to age-related models, mortality-related models revealed steeper typical rates of change consistently across all domains. At the same time, the magnitude of aging- and mortality-related effects varied widely, with some domains being more prone to exhibit mortality-related change than others. Targeting correlates of between-person disparities, we found that sociodemographic characteristics (surviving to an older age at death, being a woman, lower SES) and proxies of pathologies (comorbidities, disability, suspected dementia) were related to lower late-life functioning, whereas little evidence was found for correlates of differential change. We take our results to illustrate the pervasive nature of progressive processes leading toward death, but also the domain specificity of the size of and mechanisms underlying those effects. In the Discussion, we highlight the need for more systemic and integrated inquiries as well as more closely spaced measurements that may indicate how multiple aspects of cognitive, psychosocial, and physical function unfold together in an end-of-life "cascade."

\section{Age- and Mortality-Related Change Trajectories in Multiple Domains of Functioning}

Aging and dying are, by definition, time-related processes. The metric by which time is indexed can be considered a vehicle representing and condensing a particular complex of processes (see Wohlwill, 1973, and discussion in Ram, Gerstorf, Fauth, Zarit, \& Malmberg, 2010). Our analyses suggest that differences in change in performance-based indicators of cognitive, sensory, and physical health can be efficiently described by differences in time-to-death, whereas self-report data can be described well by either age or time-to-death differences. Although we did see similarities across domains and measures, it is conceivable and likely that other indicators in each domain can be found that are less prone to exhibiting the effects of mortality-related processes than we found for the 12 indicators used herein. For example, the mortality-related declines seen for emotional balance (see the 
Digit Letter over Age

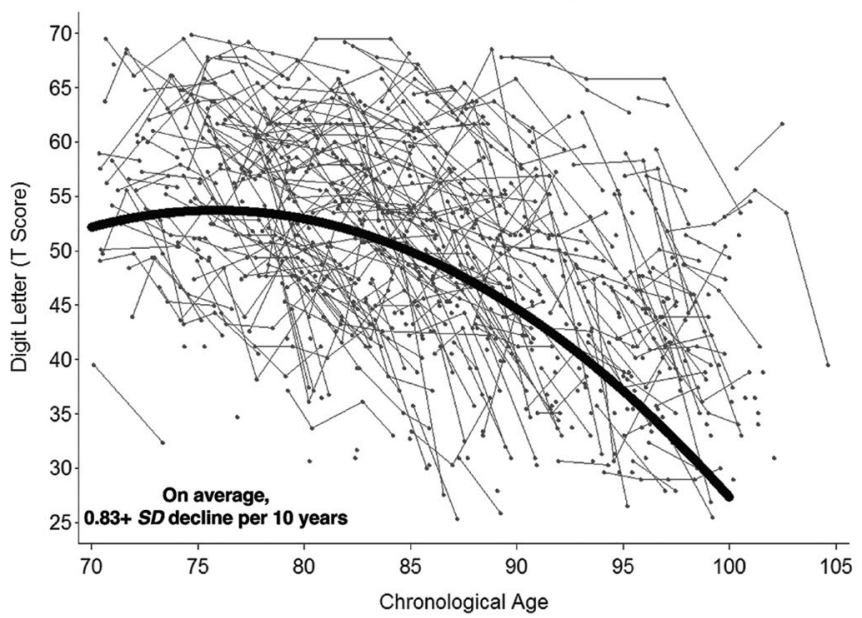

Close Vision over Age

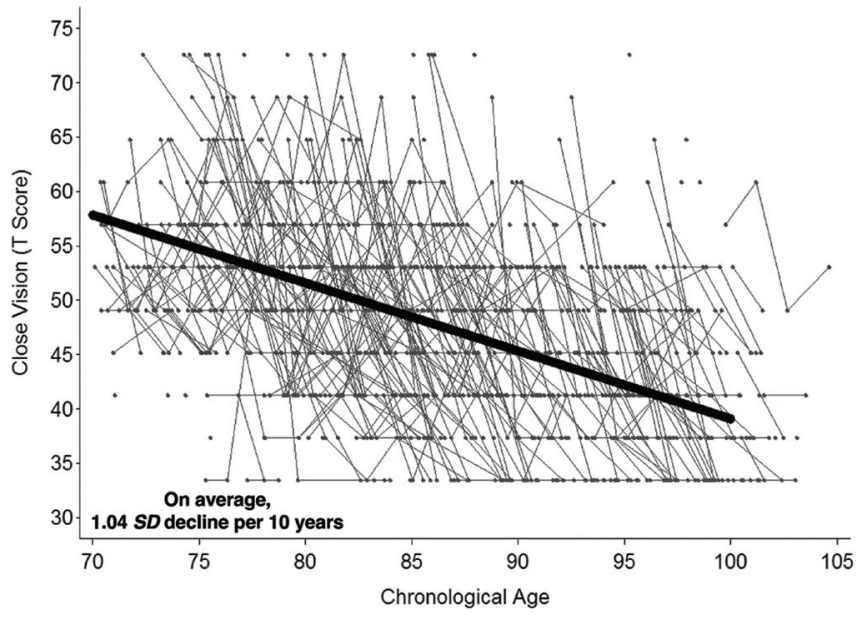

Grip Strength over Age

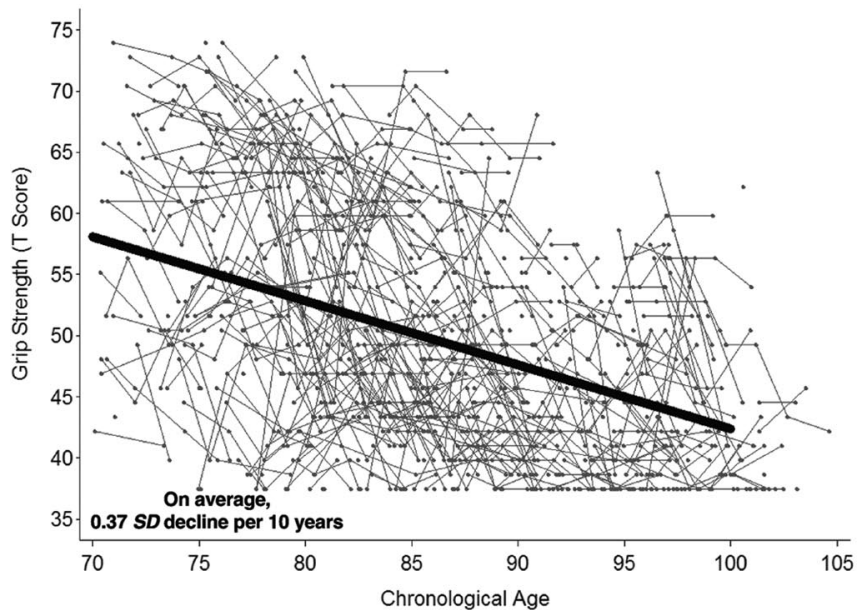

Digit Letter over Time-to-Death

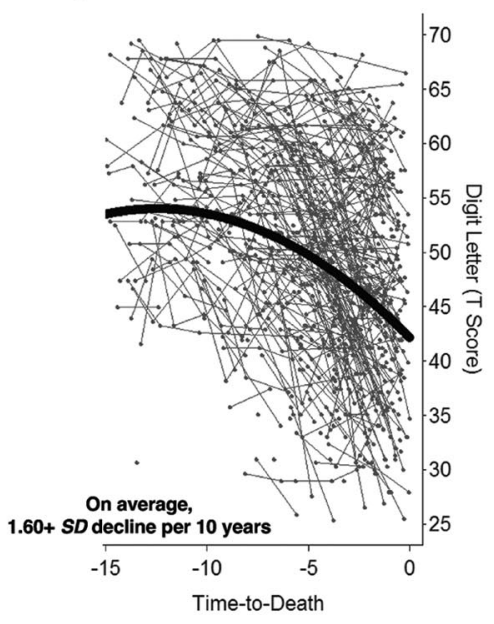

Close Vision over Time-to-Death

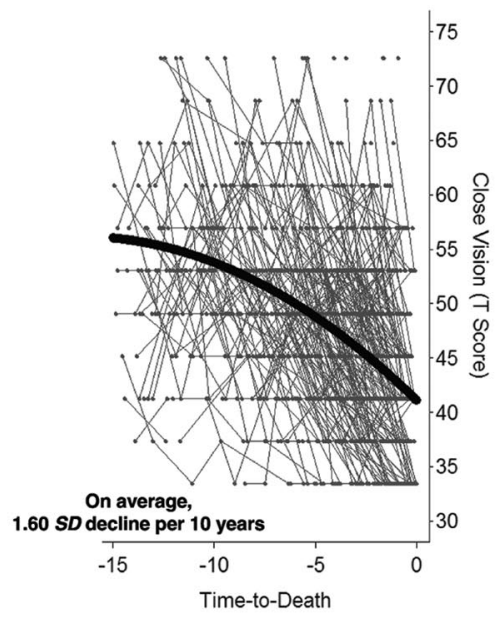

Grip Strength over Time-to-Death

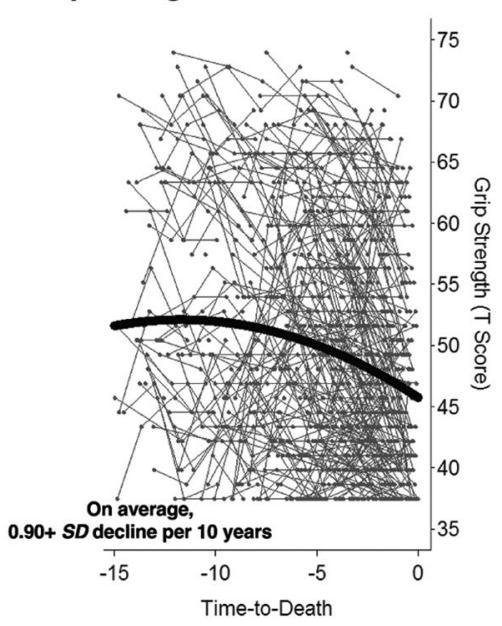

Figure 1. Individual (thin lines) and typical (thick lines) late-life trajectories of change for indicators of cognitive functioning (upper panel: Digit Letter), sensory functioning (middle panel: Close Vision), and physical functioning (lower panel: Grip strength) over chronological age (left-hand panels) and time-to-death (right-hand panels). Across domains, mortality-related models revealed steeper average rates of late-life change than did age-related models.. 
Subjective Health over Age

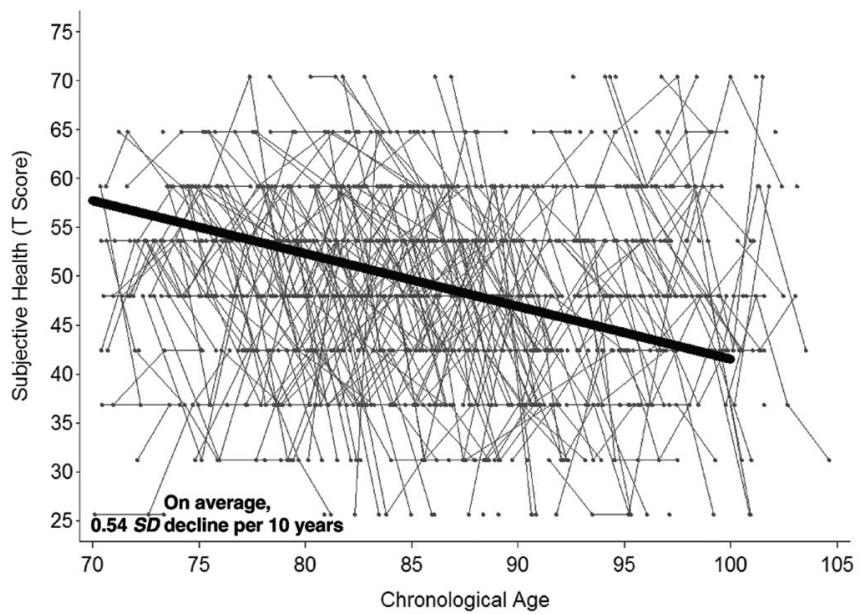

Emotional Loneliness over Age

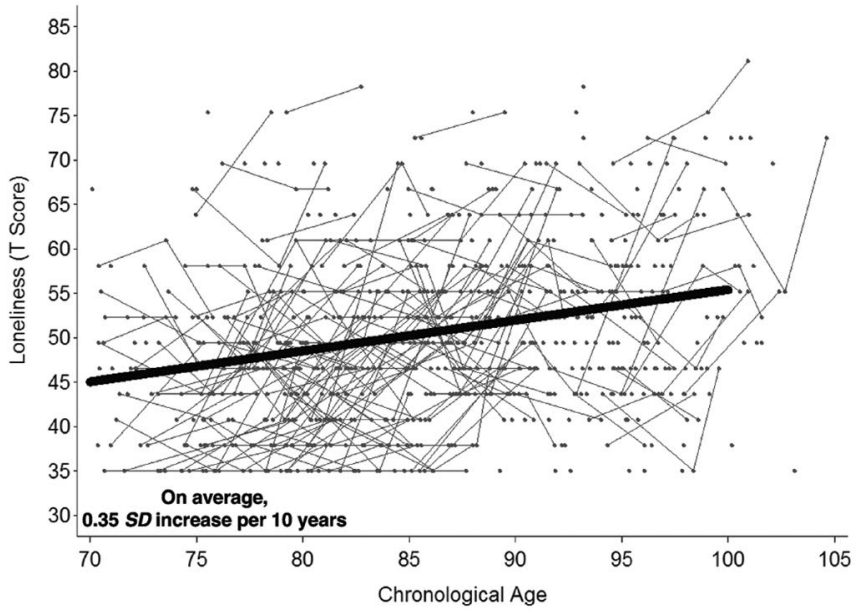

Perceived Control over Age

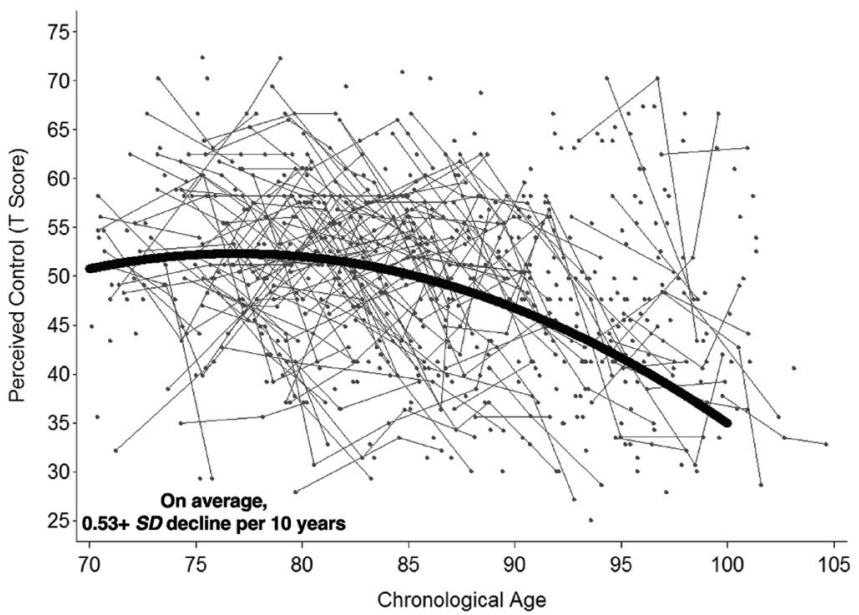

Subjective Health over Time-to-Death

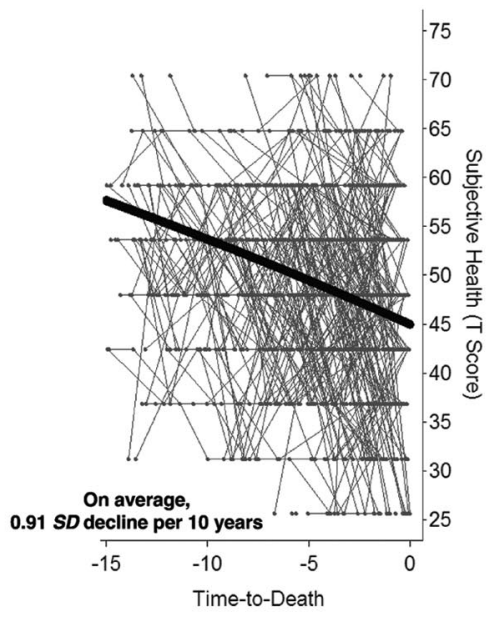

Emotional Loneliness over Time-to-Death

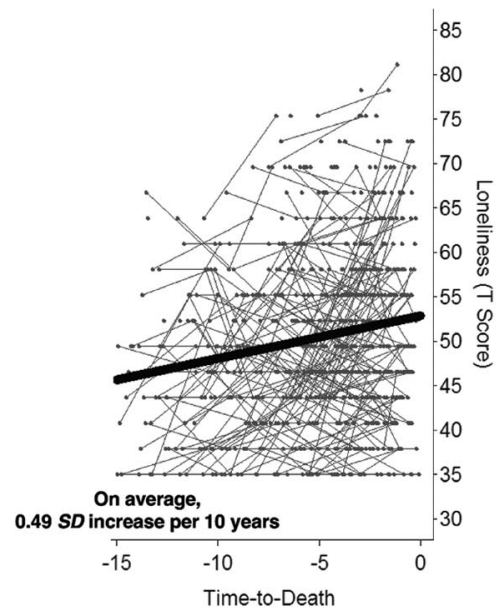

Perceived Control over Time-to-Death

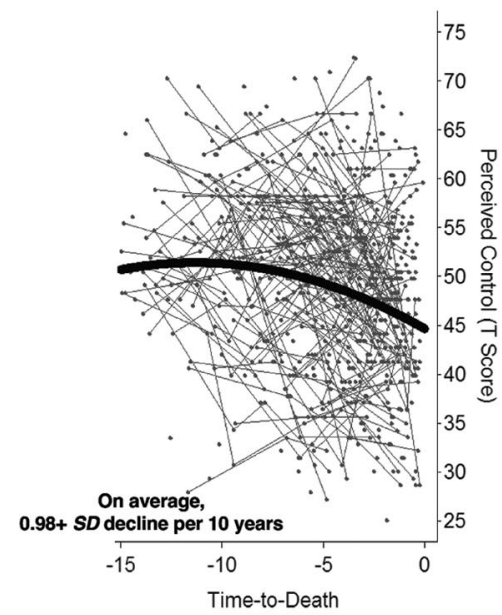

Figure 2. Individual (thin lines) and typical (thick lines) late-life trajectories of change for indicators of health (upper panel: Subjective Health), social functioning (middle panel: Emotional Loneliness), and self-related functioning (lower panel: Perceived Control) over chronological age (left-hand panels) and time-to-death (right-hand panels). Across domains, mortality-related models revealed steeper average rates of late-life change than did age-related models. 
Table 3

Growth Models for the Domain Indicators Over Time-to-Death: The Role of Between-Person Difference Factors

\begin{tabular}{|c|c|c|c|c|c|c|}
\hline Variable & $\begin{array}{l}\text { Cognitive: } \\
\text { Digit Letter } \\
\text { Estimate }(S E)\end{array}$ & $\begin{array}{c}\text { Sensory: } \\
\text { Close vision } \\
\text { Estimate }(S E)\end{array}$ & $\begin{array}{c}\text { Physical: } \\
\text { Grip strength } \\
\text { Estimate }(S E)\end{array}$ & $\begin{array}{c}\text { Health: Self-rated } \\
\text { health } \\
\text { Estimate }(S E)\end{array}$ & $\begin{array}{c}\text { Social: } \\
\text { Loneliness } \\
\text { Estimate }(S E)\end{array}$ & $\begin{array}{c}\text { Self: } \\
\text { Perceived } \\
\text { control } \\
\text { Estimate }(S E)\end{array}$ \\
\hline \multicolumn{7}{|l|}{ Fixed effects } \\
\hline Intercept, $\gamma_{o o}$ & $46.13^{*}(0.40)$ & $44.95^{*}(0.39)$ & $48.08^{*}(0.27)$ & $47.43 *(0.44)$ & $51.66 *(0.50)$ & $47.50 *(0.50)$ \\
\hline Time-to-death, $\gamma_{10}$ & $-1.56^{*}(0.11)$ & $-1.46^{*}(0.14)$ & $-0.84 *(0.10)$ & $-0.86^{*}(0.16)$ & $0.46^{*}(0.17)$ & $-0.79 *(0.18)$ \\
\hline Time-to-death ${ }^{2} \gamma_{20}$ & $-0.07^{*}(0.01)$ & $-0.05^{*}(0.02)$ & $-0.03 *(0.01)$ & $-0.04 *(0.02)$ & $0.00(0.01)$ & $-0.03(0.02)$ \\
\hline Age at death, $\gamma_{O I}$ & $-0.45^{*}(0.06)$ & $-0.34 *(0.06)$ & $-0.39 *(0.04)$ & $0.09(0.06)$ & $0.22^{*}(0.07)$ & $-0.20 *(0.07)$ \\
\hline SES, $\gamma_{02}$ & $0.25^{*}(0.04)$ & $0.09 *(0.04)$ & $0.07 *(0.03)$ & $0.08(0.04)$ & $-0.14^{*}(0.05)$ & $-0.02(0.05)$ \\
\hline Women, $\gamma_{o 3}$ & $0.49(0.81)$ & $-1.44(0.78)$ & $-9.72 *(0.56)$ & $-1.87^{*}(0.90)$ & $1.65^{*}(0.99)$ & $-2.74 *(0.99)$ \\
\hline Comorbidities, $\gamma_{04}$ & $-0.05(0.04)$ & $-0.05(0.04)$ & $-0.09^{*}(0.03)$ & $-0.09^{*}(0.04)$ & $0.11^{*}(0.05)$ & $0.01(0.05)$ \\
\hline Disability, $\gamma_{05}$ & $-2.98^{*}(0.85)$ & $-1.52(0.82)$ & $-1.66 *(0.59)$ & $-0.81(0.95)$ & $0.80(1.05)$ & $-4.46 *(1.05)$ \\
\hline Sus. dementia, $\gamma_{06}$ & $-6.68 *(0.84)$ & $-0.99(0.81)$ & $-0.85^{*}(0.58)$ & $1.23(0.93)$ & $0.67(1.03)$ & $1.31(1.03)$ \\
\hline Age at Death $\times$ Time-to-Death, $\gamma_{11}$ & $-0.03^{*}(0.01)$ & $-0.01(0.01)$ & $0.02 *(0.01)$ & $-0.01(0.01)$ & $0.00(0.01)$ & $-0.02(0.01)$ \\
\hline SES $\times$ Time-to-Death, $\gamma_{12}$ & $0.00(0.01)$ & $-0.02^{*}(0.01)$ & $0.00(0.01)$ & $-0.01(0.01)$ & $0.01(0.01)$ & $-0.01(0.01)$ \\
\hline Women $\times$ Time-to-Death, $\gamma_{13}$ & $-0.04(0.14)$ & $-0.01(0.17)$ & $0.49 *(0.11)$ & $0.19(0.16)$ & $-0.22(0.16)$ & $0.15(0.17)$ \\
\hline Comorbidities $\times$ Time-to-Death, $\gamma_{14}$ & $0.00(0.01)$ & $0.00(0.01)$ & $-0.01 *(0.00)$ & $0.01(0.01)$ & $-0.01(0.01)$ & $-0.01(0.01)$ \\
\hline Disability $\times$ Time-to-Death, $\gamma_{15}$ & $-0.32 *(0.15)$ & $-0.18(0.19)$ & $-0.29 *(0.12)$ & $0.07(0.18)$ & $0.24(0.17)$ & $-0.04(0.18)$ \\
\hline Sus. Dementia $\times$ Time-to-Death, $\gamma_{16}$ & $-0.59^{*}(0.23)$ & $0.26(0.18)$ & $0.04(0.11)$ & $0.37^{*}(0.17)$ & $0.01(0.17)$ & $0.57^{*}(0.18)$ \\
\hline Sus. Dementia $\times$ Time-to-Death ${ }^{2}, \gamma_{17}$ & $-0.06^{*}(0.02)$ & - & - & - & - & - \\
\hline \multicolumn{7}{|l|}{ Random effects } \\
\hline Intercept, $\sigma_{u 0}^{2}$ & $47.33^{*}(4.31)$ & $36.69^{*}(4.41)$ & $17.19^{*}(2.18)$ & $45.84 *(4.92)$ & $63.40^{*}(7.45)$ & $59.38 *(7.59)$ \\
\hline Time-to-death, $\sigma_{u l}^{2}$ & $0.34^{*}(0.11)$ & $0.62 *(0.15)$ & $0.01(0.00)$ & - $^{\mathrm{a}}$ & $0.07(0.14)$ & $0.03(0.18)$ \\
\hline Cov. Intercept $\times$ Time-to-Death, $\sigma_{u o u l}$ & $1.56^{*}(0.54)$ & $2.72 *(0.69)$ & $-0.37(0.26)$ & - $^{\mathrm{a}}$ & $1.42(0.98)$ & $0.53(1.00)$ \\
\hline \multicolumn{7}{|l|}{ Explained variance (between person) } \\
\hline In intercept, $\sigma_{u 0}^{2}$ & .48 & .28 & .72 & .13 & .15 & .14 \\
\hline In time-to-death, $\sigma_{u l}^{2}$ & .38 & .26 & .94 & $\underline{\mathrm{a}}^{\mathrm{a}}$ & - $^{\mathrm{a}}$ & - ${ }^{\mathrm{a}}$ \\
\hline Residual, $\sigma_{e}^{2}$ & $11.47^{*}(0.83)$ & $26.89^{*}(1.80)$ & $17.47 *(0.97)$ & $44.75^{*}(2.51)$ & $28.36^{*}(2.87)$ & $32.05 *(3.53)$ \\
\hline
\end{tabular}

Note. Ns range between 404 (Digit Letter) and 438 (perceived control) who provided between 739 (perceived control) and 1,076 observations (close vision). Unstandardized estimates and standard errors are presented. Intercept is located at 2 years prior to death. Level 2 versions of time-to-death were not included because many of these were previously found to be nonsignificant. SES = socioeconomic status; Sus. Dementia = Suspected dementia; Cov. intercept $=$ Covariance intercept. Dashes indicate that effect was not estimated.

${ }^{a}$ For model convergence, variance of time-to-death and Covariance Intercept $\times$ Time-to-Death could not be estimated.

$* p<.05$

Appendix) were primarily driven by positive affect, whereas negative affect remained relatively flat both over chronological age and time-to-death. Given that the sensitivity of the negative affect items of the Positve and Negative Affect Scheudule (PANAS; Watson, Clark, \& Tellegen, 1988) in capturing within-person change is relatively low, we do not want to overinterpret the apparent discrepancy between positive and negative affect. Descriptively, this finding may point to the existence of variables/ domains that are less affected by the deleterious late-life changes seen in many other areas of late life.

Included in our study were domains known to be sensitive to age-related change throughout adulthood, and domains that are relatively age-insensitive. For example, the increasing rigidity of the crystalline lens is known to reduce the eye's capacity to focus on very near objects - with age-related decrements in close visual acuity already apparent by mid-adulthood (see Lindenberger \& Baltes, 1997). In contrast, we also examined more qualitative aspects of social support, such as feelings of loneliness, or selfrelated function, such as perceived control, that typically show rather minor age-related change (Antonucci, 2001; Lachman, 2006). Although the average rates of change differed across the six domains targeted here, the general pattern suggested that all domains show steep mortality-related change. Our study is one of the first reports (for a notable exception, see Diehr et al., 2002) to demonstrate empirically that mortality-related processes are a pervasive phenomenon that affects many different domains. Consistent with theoretically based expectations, the magnitude of agingand mortality-related effects was not uniform across the six domains examined. This finding can be interpreted to indicate that different constellations of factors contribute to change in each domain. Some domains may be more related to biological-level processes (e.g., sensory), whereas other domains are more strongly affected by social-level processes (e.g., loneliness), and still others by some combination of these as well as physical health and frailty (e.g., self-related). Following Baltes and Smith (2003), dying in late life expresses the most incomplete aspect of human ontogeny. Rather than following a biological program, mortality-related processes may operate as chaotic systemic dysregulation that contribute to the emergence (or enhancement) of associations between previously independent processes and the breakdown of associations that were previously present (Rieckmann et al., 2011). It is an open question whether such breakdown is triggered by or a precursor of surpassing lower limits of performance or behavior that foreshadow imminent death (see discussion of lethal limits in Riegel \& Riegel, 1972). Our study is primarily descriptive in nature and was not designed to tether mortality-related changes to particular causal mechanisms. More process-oriented studies are needed to thoroughly address the above speculations. 
If our general pattern of results were corroborated in future studies, important implications arise for the study of aging and late life. Dying appears to include processes that are not (fully) captured in examinations of normative age-graded processes. The nominal differences in the rates of change obtained in the age and time-to-death models (e.g., self-rated health: $-0.54 \mathrm{~T}$-score units per year for age vs. $-0.91 \mathrm{~T}$-score units per year for time-to-death) provide a rough quantification of the differences between mortality-related and age-related effects (Sliwinski et al., 2006). We note, however, that time-to-death is highly similar to age in that both are time-related catch-all variables that serve as a proxy for how a variety of underlying factors progress through time. The crucial task for future research is to move away from such timerelated representations and toward an explicit consideration of how underlying mechanisms unfold (e.g., accumulating pathologies or disability).

\section{The Role of Sociodemographic Characteristics and Proxies of Pathologies}

Over and above the typical rates of late-life change, our models also revealed sizable between-person differences in the rate of mortality-related decline. Our findings indicate that sociodemographic characteristics and proxies of pathologies both play a pivotal role in late-life functioning and change, but also suggest that much more needs to be learned about how differences in mortality-related change accrue (using study designs that have better power to detect correlates of change).

Our results on the correlates of late-life function and change are in line with extant reports from age-based investigations. Although we expected that mortality and pathology burden are the most important drivers of late-life change across the domains considered, we also acknowledged that the size of these effects likely differs with chronological age. For example, consistent with the view that the oldest old are at the limits of their adaptive capacity, the literature suggests an increased likelihood and contribution of pathology-based dysfunctionality in advanced old age relative to earlier phases of old age (see Baltes \& Smith, 2003). In line with this reasoning, we found that impending mortality exerts more detrimental effects on functionality in older ages. Regarding gender, Smith, Borchelt, et al. (2002) reported from an earlier analysis in the BASE that handgrip strength of 70-year-old men was, on average, $21 \mathrm{~kg}$, whereas for the typical 70-year-old woman, it was $8 \mathrm{~kg}$. At age 90, this was reduced to an average of $12 \mathrm{~kg}$ for men and $2 \mathrm{~kg}$ for women. At 2 years prior to death, we found the same pattern with men being physically stronger than women, an estimated effect that amounted to almost a full standard deviation (see Table 3, or $13.2 \mathrm{~kg}$ for men vs. $3.8 \mathrm{~kg}$ for women). Finally, our results also corroborate that people in higher socioeconomic strata face the challenges of late life at higher functional levels (for discussion, see Mirowsky \& Ross, 2007). We note, however, that generalizability may be limited from data gathered from a metropolitan sample of residents of the former city of West Berlin with its unique historic constellation (Baltes \& Mayer, 1999).

To move toward a more integrated understanding of late-life change, we examined how outcomes of pathologies impact mortality-related change. We targeted burdens imposed by medically diagnosed moderate to severe physical illnesses as well as prevalence of disability and suspected dementia throughout the course of our study. Several of these burdens were found to show reliable associations with between-person differences in late-life function and rates of change. For example, persons suffering from disability reported levels of perceived control at 2 years prior to death that were almost half a standard deviation below those of nondisabled participants. These disabled participants also showed steeper mortality-related cognitive declines than persons who remained free of disability throughout their lives. We take these results to highlight the utility of targeting the role that pathologiesrelated processes play in the rate of late-life deterioration.

Several notes of caution must be conveyed. First, additional mechanisms appear to be at work, as exemplified by our finding that cognitive impairments were associated with shallower late-life declines in self-rated health and perceived control. It is possible that people who are cognitively impaired may be less able to accurately assess their health or level of control. Second, the result that pathologies and disability were not consistently linked with steeper end-of-life change across all domains can be interpreted as another indication of the domain specificity of the mechanisms underlying those changes. Alternatively, these discrepancies may simply indicate that the currently available measures and designs are not well suited to examine how the processes leading toward death unfold over time. For example, 2-year spacing of measurement occasions may be too long to fully capture any systematic local "accelerations" in how mortality-related processes progress. Third, we treated pathologies as a time-invariant between-person characteristic. A crucial next step would be to shift toward considering pathologies as a time-varying within-person characteristic that develops over time, and how the ongoing accumulation (or reduction) of diseases and disability affects mortality-related functional changes. To illustrate, although prominent biopsychosocial theories of late life implicate disablement as a major force underlying developmental change (Verbrugge \& Jette, 1994), looking at disability in a more process-oriented manner has rarely been done, probably because an operationalization of the disablement process approach requires measures that track the continuous progression of disability. Under the assumption that pathologies indeed form entities that are etiologically distinct from other syndromes preceding death, aligning functional changes in the six domains considered along the timing and progression of pathologies should yield better descriptions than a time-to-death metric because this index is conceptually closer to the underlying mechanisms than is mortality (Ram et al., 2010).

\section{Limitations and Outlook}

We selected the six domains examined in this study to broadly sample key functional systems at the end of life. Per domain, we chose a measure that is established in research on old age and, with an interest in within-person change, was available at multiple measurement occasions. We acknowledge that our selection was restricted by the indicators that were included in the longitudinal assessment battery of the BASE and that the inclusion of both further indicators per domain (e.g., number of medical diagnoses) and an extension of the domains considered would have been feasible (e.g., activities, motivation, emotion regulation, brain efficiency). We also note that our focus on medically diagnosed physical illnesses at baseline assessment has certainly been a suboptimal index of the medical burdens of interest and did not 
offset the limitations imposed by the lack of reliable data on causes of death (Maudsley \& Williams, 1996). For example, cause of death and the specific pathologies that accumulate may differentiate between various forms of decline. Individuals dying from neoplasms may show slow but steady decline, whereas people dying from acute vascular diseases (stroke or heart attack) may exhibit exacerbated decline, and a third group of people dying from accidents may show no or minimal signs of decline because their bodies and minds have not had the chance to manifest the full force of mortality-related processes (see MacDonald, Hultsch, \& Dixon, 2011).

Given the relatively unidirectional results of our study regarding the nature of late-life change, a natural next step is to target the overlap of and possibly common mechanisms underlying late-life change between functional domains. One way to do so would have been to apply multivariate growth models and examine interrelations between the simultaneously estimated level and change factors across the six domains of functioning (for examples regarding age-related changes, see Ghisletta, Rabbitt, Lunn, \& Lindenberger, 2012; Tucker-Drob, 2011). However, three of the six domain indicators did not reveal reliable between-person differences in change, thereby precluding this route of investigation. We caution that this may not necessarily represent a substantive phenomenon, but rather a lack of statistical power to examine the question of interest (Hertzog, Lindenberger, Ghisletta, \& von Oertzen, 2006). In addition, although we modeled quadratic trends, the ability to detect between-person differences in those trends was limited by the fact that relatively few participants provided four or more data points (111 participants, 25\% of the sample). With more data points and more closely spaced assessments, notions of terminal decline could be operationalized even more directly via multiphase models of change that estimate the point of onset of terminal decline and between-person differences therein (see, e.g., Gerstorf, Ram, Estabrook, et al., 2008). Furthermore, the modeling approach used in this study could be complemented by models that combine longitudinal growth curve modeling with survival analyses to estimate the influence that level and change in the constructs of interest have on age at death (e.g., Ghisletta, McArdle, \& Lindenberger, 2006). Finally, inspired by work in neighboring disciplines (e.g., Baudisch, 2011), it may be worthwhile to fit models of aging and mortality risk that are nonlinear in the parameters (e.g., exponential decline functions). More generally, articulating and testing multidimensional notions of late-life change will expand the theoretical framework from which terminal decline has been studied and provide an integrated picture of how and potential reasons why some individuals age more successfully than others (e.g., experience less decline prior to death). The results of this study provide an impetus for future inquiry of how terminal decline proceeds systemically and at multiple levels of study.

In closing, to eventually inform the design of prevention and intervention efforts, it is pivotal to provide a correct description of the actual amount of late-life declines. Thoroughly demonstrating that late-life declines are much more serious and steeper as compared with what one would expect on the basis of extant age models may alert society and policy makers to this largely unnoticed phenomena and to eventually allocate the resources necessary that may help alleviate those declines in the future. For example, knowing that a person has entered the death track ideally does not affect the net sum of health care expenditures, but the way those expenditures are made. Through a careful and well-balanced strategy, it may well be possible to devote those resources toward maintaining quality of life and allowing the person to die with a sense of dignity rather than toward extending the length of life for as long as possible. To live up to this promise, we need to move toward prospective models that predict mortality risk as a function of decline and that pinpoint the degree to which late-life decrements in one domain coincide with late-life decrements in other domains and how accumulating pathologies overlap with and contribute to mortality-related changes.

\section{References}

Alwin, D. F., Hofer, S. M., \& McCammon, R. J. (2006). Modeling the effects of time: Integrating demographic and developmental perspectives. In R. H. Binstock \& L. K. George (Eds.), Handbook of aging and the social sciences (6th ed., pp. 20-38). New York, NY: Elsevier. doi:10.1016/B978-012088388-2/50005-5

Anstey, K., Stankov, L., \& Lord, S. (1993). Primary aging, secondary aging, and intelligence. Psychology and Aging, 8, 562-570. doi:10.1037/ 0882-7974.8.4.562

Antonucci, T. C. (2001). Social relations: An examination of social networks, social support, and sense of control. In J. E. Birren (Ed.), Handbook of the psychology of aging (pp. 427-453). San Diego, CA: Academic Press.

Bäckman, L., \& MacDonald, S. W. S. (2006). Death and cognition: Synthesis and outlook. European Psychologist, 11, 224-235.

Baltes, P. B., Lindenberger, U., \& Staudinger, U. M. (2006). Life-span theory in developmental psychology. In R. M. Lerner (Ed.), Handbook of child psychology Vol. 1: Theoretical models of human development (6th ed., pp. 569-664). New York, NY: Wiley.

Baltes, P. B., \& Mayer, K. U. (Eds.). (1999). The Berlin Aging Study: Aging from 70 to 100. New York, NY: Cambridge University Press.

Baltes, P. B., \& Smith, J. (2003). New frontiers in the future of aging: From successful aging of the young old to the dilemmas of the fourth age. Gerontology, 49, 123-135. doi:10.1159/000067946

Baudisch, A. (2011). The pace and shape of ageing. Methods in Ecology and Evolution, 2, 375-382. doi:10.1111/j.2041-210X.2010.00087.x

Berg, A. I., Hassing, L. B., Thorvadsson, V., \& Johansson, B. (2011). Personality and personal control make a difference for life satisfaction in the oldest-old: Findings in a longitudinal population-based study of individuals 80 and older. European Journal of Ageing, 8, 13-20.

Birren, J. E., \& Cunningham, W. (1985). Research on the psychology of aging: Principles, concepts, and theory. In J. E. Birren \& K. W. Schaie (Eds.), Handbook of the psychology of aging (2nd ed., pp. 3-34). New York, NY: Van Nostrand Reinhold.

Brandtstädter, J., \& Greve, W. (1994). The aging self: Stabilizing and protective processes. Developmental Review, 14, 52-80. doi:10.1006/ drev.1994.1003

Carstensen, L. L., Isaacowitz, D. M., \& Charles, S. T. (1999). Taking time seriously: A theory of socioemotional selectivity. American Psychologist, 54, 165-181. doi:10.1037/0003-066X.54.3.165

Carver, C. S. (1998). Resilience and thriving: Issues, models, and linkages. Journal of Social Issues, 54, 245-266. doi:10.1111/j.1540-4560.1998 tb01217.x

Cattell, R. B. (1971). Abilities: Their structure, growth, and action. Boston, MA: Houghton Mifflin.

Christensen, H., Mackinnon, A. J., Korten, A., \& Jorm, A. F. (2001). The common cause hypothesis of cognitive aging: Evidence for not only a common factor but also specific associations of age with vision and grip strength in a cross-sectional analysis. Psychology and Aging, 16, 588599. doi:10.1037/0882-7974.16.4.588

Crimmins, E. M., Hayward, M. D., \& Saito, Y. (1996). Differentials in active life expectancy in the older population of the United States. 
Journal of Gerontology: Series B: Psychological Sciences, 51, S111S120. doi:10.1093/geronb/51B.3.S111

Cristofalo, J. J., Tresini, M., Francis, M. K., \& Volker, C. (1999). Biological theories of senescence. In V. L. Bengtson \& K. W. Schaie (Eds.), Handbook of theories of aging (pp. 98-112). New York, NY: Springer.

Diehr, P., Williamson, J., Burke, G. L., \& Psaty, B. M. (2002). The aging and dying processes and the health of older adults. Journal of Clinical Epidemiology, 55, 269-278. doi:10.1016/S0895-4356(01)00462-0

Featherman, D. L., \& Petersen, T. (1986). Markers of aging: Modeling the clocks that time us. Research on Aging, 8, 339-365. doi:10.1177/ 0164027586008003001

Finch, C. E., \& Kirkwood, T. B. L. (2000). Chance, development, and aging. New York, NY: Oxford University Press.

Fozard, J. L., \& Gordon-Salant, A. (2001). Changes in vision and hearing with aging. In J. E. Birren \& K. W. Schaie (Eds.), Handbook of the psychology of aging (5th ed., pp. 241-266). San Diego, CA: Academic Press.

Gerstorf, D., Ram, N., Estabrook, R., Schupp, J., Wagner, G. G., \& Lindenberger, U. (2008). Life satisfaction shows terminal decline in old age: Longitudinal evidence from the German Socio-Economic Panel Study (SOEP). Developmental Psychology, 44, 1148-1159. doi: 10.1037/0012-1649.44.4.1148

Gerstorf, D., Ram, N., Mayraz, G., Hidajat, M., Lindenberger, U., Wagner, G. G., \& Schupp, J. (2010). Late-life decline in well-being across adulthood in Germany, the United Kingdom, and the United States: Something is seriously wrong at the end of life. Psychology and Aging, 25, 477-485. doi:10.1037/a0017543

Gerstorf, D., Ram, N., Röcke, C., Lindenberger, U., \& Smith, J. (2008). Decline in life satisfaction in old age: Longitudinal evidence for links to distance-to-death. Psychology and Aging, 23, 154-168. doi:10.1037/ 0882-7974.23.1.154

Ghisletta, P., McArdle, J. J., \& Lindenberger, U. (2006). Longitudinal cognition-survival relations in old and very old age: 13-year data from the Berlin Aging Study. European Psychologist, 11, 204-223. doi: 10.1027/1016-9040.11.3.204

Ghisletta, P., Rabbitt, P. M. A., Lunn, M., \& Lindenberger, U. (2012). Two thirds of the age-based changes in fluid and crystallized intelligence, perceptual speed, and memory in adulthood are shared. Intelligence, 40 , $260-268$.

Hawkley, L. C., \& Cacioppo, J. T. (2007). Aging and loneliness: Downhill quickly? Current Directions in Psychological Sciences, 16, 187-191. doi:10.1111/j.1467-8721.2007.00501.x

Heckhausen, J., \& Schulz, R. (1995). A life-span theory of control. Psychological Review, 102, 284-304. doi:10.1037/0033-295X.102.2.284

Hertzog, C., Lindenberger, U., Ghisletta, P., \& von Oertzen, T. (2006). On the power of multivariate latent growth curve models to detect correlated change. Psychological Methods, 11, 244-252. doi:10.1037/1082-989X .11.3.244

Horn, J. L. (1982). The theory of fluid and crystallized intelligence in relation to concepts of cognitive psychology and aging in adulthood. In F. I. M. Craik \& S. Trehub (Eds.), Aging and cognitive processes (pp. 237-278). New York, NY: Plenum Press. doi:10.1007/978-1-46844178-9 14

Idler, E. L. (1993). Age differences in self-assessments of health: Age changes, cohort differences, or survivorship? Journal of Gerontology, 48, S289-S300. doi:10.1093/geronj/48.6.S289

Kahn, R. L., \& Antonucci, T. C. (1980). Convoys over the life course: Attachment, roles, and social support. In P. B. Baltes \& O. G. Brim Jr. (Eds.), Life-span development and behavior (Vol. 3, pp. 253-286). New York, NY: Academic Press.

Kleemeier, R. W. (1962). Intellectual changes in the senium. Proceedings of the Social Statistics Section of the American Statistical Association, 1, 290-295.
Klein, L. E., Roca, R. P., McArthur, J., Vogelsang, G., Klein, G. B., Kirby, S. M., \& Folstein, M. (1985). Diagnosing dementia. Univariate and multivariate analyses of the mental status examination. Journal of the American Geriatrics Society, 33, 483-488.

Kline, D. W., \& Scialfa, C. T. (1996). Visual and auditory aging. In J. E. Birren \& K. W. Schaie (Eds.), Handbook of psychology of aging (4th ed., pp. 181-203). New York, NY: Academic Press.

Kotter-Gruehn, D., Gruehn, D., \& Smith, J. (2010). Predicting one's own death: The relationship between subjective and objective nearness to death in very old age. European Journal of Ageing, 7, 293-300. doi: 10.1007/s10433-010-0165-1

Kotter-Grühn, D., Kleinspehn-Ammerlahn, A., Gerstorf, D., \& Smith, J. (2009). Self-perceptions of aging predict mortality and change with approaching death: 16-year longitudinal results from the Berlin Aging Study. Psychology and Aging, 24, 654-667. doi:10.1037/a0016510

Krause, N., \& Shaw, B. A. (2003). Role-specific control, personal meaning, and health in late life. Research on Aging, 25, 559-586. doi $10.1177 / 0164027503256695$

Lachman, M. E. (2006). Perceived control over aging-related declines: Adaptive beliefs and behaviors. Current Directions in Psychological Science, 15, 282-286. doi:10.1111/j.1467-8721.2006.00453.x

Lindenberger, U., \& Baltes, P. B. (1997). Intellectual functioning in old and very old age: Cross-sectional results from the Berlin Aging Study. Psychology and Aging, 12, 410-432. doi:10.1037/0882-7974.12.3.410

Lindenberger, U., \& Ghisletta, P. (2009). Cognitive and sensory decline in old age: Gauging the evidence for a common cause. Psychology and Aging, 24, 1-16. doi:10.1037/a0014986

Lindenberger, U., Singer, T., \& Baltes, P. B. (2002). Longitudinal selectivity in aging populations: Separating mortality-associated versus experimental components in the Berlin Aging Study (BASE). Journals of Gerontology: Series B: Psychological Sciences, 57, P474-P482. doi: 10.1093/geronb/57.6.P474

Littell, R. C., Miliken, G. A., Stoup, W. W., \& Wolfinger, R. D. (1996). SAS system for mixed models. Cary, NC: SAS Institute.

Little, R. J. A., \& Rubin, D. B. (1987). Statistical analysis with missing data. New York, NY: Wiley.

Lövdén, M., Ghisletta, P., \& Lindenberger, U. (2005). Social participation attenuates decline in perceptual speed in old and very old age. Psychology and Aging, 20, 423-434. doi:10.1037/0882-7974.20.3.423

MacDonald, S. W. S., Hultsch, D. F., \& Dixon, R. A. (2011). Aging and the shape of cognitive change before death: Terminal decline or terminal drop? Journals of Gerontology: Series B: Psychological Sciences, 66 , 292-301.

Maier, H., \& Smith, J. (1999). Psychological predictors of mortality in old age. Journals of Gerontology: Series B: Psychological Sciences, 54 P44-P54. doi:10.1093/geronb/54B.1.P44

Maudsley, G., \& Williams, E. M. (1996). 'Inaccuracy' in death certification-where are we now? Journal of Public Health and Medicine, 18, 59-66. doi:10.1093/oxfordjournals.pubmed.a024463

McArdle, J. J. (1994). Structural factor analysis experiments with incomplete data. Multivariate Behavioral Research, 29, 409-454. doi: $10.1207 / \mathrm{s} 15327906 \mathrm{mbr} 29045$

Mirowsky, J., \& Ross, C. E. (2007). Life-course trajectories of perceived control and their relationship to education. American Journal of Sociology, 112, 1339-1382. doi:10.1086/511800

Moen, P. (1996). Gender, age, and the life course. In R. H. Binstock \& L. K. George (Eds.), Handbook of aging and the social sciences (4th ed. pp. 171-187). San Diego, CA: Academic Press.

Mroczek, D. K., \& Spiro, A., III. (2005). Change in life satisfaction during adulthood: Findings from the Veterans Affairs Normative Aging Study. Journal of Personality and Social Psychology, 88, 189-202. doi 10.1037/0022-3514.88.1.189

Palgi, Y., Shrira, A., Ben-Ezra, M., Spalter, T., Shmotkin, D., \& Kavé, G. (2010). Delineating terminal change in subjective well-being and sub- 
jective health. Journals of Gerontology: Series B: Psychological Sciences, 65, 61-64. doi:10.1093/geronb/gbp095

Ram, N., Gerstorf, D., Fauth, B., Zarit, S. H., \& Malmberg, B. (2010). Aging, disablement, and dying: Using time-as-process and time-asresources metrics to chart late-life change. Research in Human Development, 7, 27-44. doi:10.1080/15427600903578151

Ram, N., \& Grimm, K. J. (2007). Using simple and complex growth models to articulate developmental change: Matching method to theory. International Journal of Behavioral Development, 31, 303-316. doi: $10.1177 / 0165025407077751$

Rieckmann, A., Karlsson, S., Karlsson, P., Brehmer, Y., Fischer, H., \& Bäckman, L. (2011). Dopamine d1 receptor associations within and between dopaminergic pathways in younger and elderly adults: Links to cognitive performance. Cerebral Cortex, 21, 2023-2032.

Riegel, K. F., \& Riegel, R. M. (1972). Development, drop, and death. Developmental Psychology, 6, 306-319. doi:10.1037/h0032104

Russell, D., Cutrona, C. E., Rose, J., \& Yurko, K. (1984). Social and emotional loneliness: An examination of Weiss's typology of loneliness. Journal of Personality and Social Psychology, 46, 1313-1321. doi: 10.1037/0022-3514.46.6.1313

Salthouse, T. A. (1991). Theoretical perspectives on cognitive aging. Hillsdale, NJ: Erlbaum.

Salthouse, T. A. (2004). What and when of cognitive aging. Current Directions in Psychological Science, 13, 140-144. doi:10.1111/j.09637214.2004.00293.x

Sargent-Cox, K. A., Anstey, K. J., \& Luszcz, M. A. (2010). Patterns of longitudinal change in older adults' self-rated health. Health Psychology, 29, 143-152. doi:10.1037/a0017652

Schaie, K. W. (2005). Developmental influences on intelligence: The Seattle Longitudinal Study. New York, NY: Oxford University Press. doi:10.1093/acprof:oso/9780195156737.001.0001

Singer, J. D., \& Willett, J. B. (2003). Applied longitudinal data analysis: Modeling change and event occurrence. New York, NY: Oxford University Press.

Sliwinski, M., Hoffman, L., \& Hofer, S. M. (2010). Evaluating convergence of within-person change and between-person age differences in age-heterogeneous longitudinal studies. Research in Human Development, 7, 45-60. doi:10.1080/15427600903578169

Sliwinski, M. J., Stawski, R. S., Hall, R. B., Katz, M., Verghese, J., \& Lipton, R. B. (2006). On the importance of distinguishing pre-terminal and terminal cognitive decline. European Psychologist, 11, 172-181. doi:10.1027/1016-9040.11.3.172
Smith, J., Borchelt, M., Maier, H., \& Jopp, D. (2002). Health and wellbeing in the young old and the oldest old. Journal of Social Issues, 58 715-732. doi:10.1111/1540-4560.00286

Smith, J., Maas, I., Mayer, K. U., Helmchen, H., Steinhagen-Thiessen, E., \& Baltes, P. B. (2002). Two-wave longitudinal findings from the Berlin Aging Study: Introduction to a collection of articles. Journals of Gerontology: Series B: Psychological Sciences, 57, P471-P473. doi: 10.1093/geronb/57.6.P471

Snijders, T. A. B., \& Bosker, R. J. (1999). Multilevel analysis: An introduction to basic and advanced multilevel modeling. London, UK: Sage.

Steinhagen-Thiessen, E., \& Borchelt, M. (1999). Morbidity, medication, and functional limitations in very old age. In P. B. Baltes \& K. U. Mayer (Eds.), The Berlin Aging Study: Aging from 70 to 100 (pp. 131-166). New York, NY: Cambridge University Press.

Stern, Y. (2002). What is cognitive reserve? Theory and research application of the reserve concept. Journal of the International Neuropsychological Society, 8, 448-460. doi:10.1017/S1355617702813248

Tucker-Drob, E. M. (2011). Neurocognitive functions and everyday functions change together in old age. Neuropsychology, 25, 368-377.

Verbrugge, L. M., \& Jette, A. M. (1994). The disablement process. Social Science and Medicine, 38, 1-14. doi:10.1016/0277-9536(94)90294-1

Verhaeghen, P., Borchelt, M., \& Smith, J. (2003). Relation between cardiovascular and metabolic disease and cognition in very old age: Crosssectional and longitudinal findings from the Berlin Aging Study. Health Psychology, 22, 559-569. doi:10.1037/0278-6133.22.6.559

Watson, D., Clark, L. A., \& Tellegen, A. (1988). Development and validation of brief measures of Positive and Negative Affect: The PANAS Scales. Journal of Personality and Social Psychology, 54, 1063-1070. doi:10.1037/0022-3514.54.6.1063

Wechsler, D. (1982). Handanweisung zum Hamburg-WechslerIntelligenztest fuer Erwachsene (HAWIE) [Manual for the Hamburg Wechsler Intelligence Tests for adults]. Bern, Switzerland: Huber.

Wilson, R. S., Beck, T. L., Bienias, J. L., \& Bennett, D. A. (2007). Terminal cognitive decline: Accelerated loss of cognition in the last years of life. Psychosomatic Medicine, 69, 131-137. doi:10.1097/PSY .0b013e31803130ae

Wilson, R. S., Beckett, L. A., Bienias, J. L., Evans, D. A., \& Bennett, D. A. (2003). Terminal decline in cognitive function. Neurology, 60, 1782 1787. doi:10.1212/01.WNL.0000068019.60901.C1

Wohlwill, J. F. (1973). The study of behavioral development. Oxford, UK: Academic Press. 


\section{Appendix}

\section{Growth Models for Alternative Indicators of Cognitive, Sensory, Physical, Health, Social, and Self-Related Functions Over Age and Time-to-Death}

\begin{tabular}{|c|c|c|c|c|c|c|c|c|c|c|}
\hline \multirow[b]{2}{*}{ Time metric } & \multicolumn{3}{|c|}{ Fixed effects } & \multicolumn{2}{|c|}{ Level 2} & \multicolumn{4}{|c|}{ Random effects } & \multirow{2}{*}{$\frac{\text { Model fit }}{\Delta \text { Pseudo } R^{2}}$} \\
\hline & Intercept, $\gamma_{00}$ & $\begin{array}{c}\text { Linear slope, } \\
\gamma_{01}\end{array}$ & $\begin{array}{l}\text { Quadratic } \\
\text { slope, } \gamma_{02}\end{array}$ & Age/Ttd & $\begin{array}{l}\text { Age } / \text { Ttd } \times \\
\text { Linear Slope }\end{array}$ & $\begin{array}{l}\text { Variance in- } \\
\text { tercept }\end{array}$ & $\begin{array}{l}\text { Variance } \\
\text { slope }\end{array}$ & Covariance & $\begin{array}{l}\text { Residual vari- } \\
\text { ance }\end{array}$ & \\
\hline \multicolumn{11}{|c|}{ Cognitive: Categories } \\
\hline $\begin{array}{l}\text { Age } \\
95 \% \mathrm{CI}\end{array}$ & $50.41^{*}(0.62)$ & $\begin{array}{c}-0.33^{*}(0.09) \\
{[-0.81,0.15]}\end{array}$ & $-0.03^{*}(0.01)$ & $-0.23^{*}(0.10)$ & $0.04^{*}(0.01)$ & $61.26^{*}(5.62)$ & $0.06(0.05)$ & $0.07(0.33)$ & $24.32^{*}(1.45)$ & .147 \\
\hline $\begin{array}{l}\text { Mortality } \\
95 \% \text { CI }\end{array}$ & $49.05^{*}(0.57)$ & $\begin{array}{c}-1.16^{*}(0.14) \\
{[-2.14,0.18]}\end{array}$ & $-0.12^{*}(0.02)$ & $-0.38^{*}(0.13)$ & $0.14^{*}(0.03)$ & $76.15^{*}(6.66)$ & $0.25^{*}(0.11)$ & $2.14^{*}(0.72)$ & $22.07^{*}(1.39)$ & .226 \\
\hline \multicolumn{11}{|l|}{$\begin{array}{l}\text { Sensory: Hearing } \\
\text { acuity }\end{array}$} \\
\hline $\begin{array}{l}\text { Age } \\
\quad 95 \% \mathrm{CI}\end{array}$ & $48.79^{*}(0.55)$ & $\begin{array}{r}-0.37^{*}(0.08) \\
{[-0.65,-0.09]}\end{array}$ & $-0.04^{*}(0.01)$ & $-0.18^{*}(0.09)$ & $0.05(0.01)$ & $53.14^{*}(4.49)$ & $0.02(0.04)$ & $-0.97^{*}(0.29)$ & $19.27^{*}(1.30)$ & .179 \\
\hline $\begin{array}{c}\text { Mortality } \\
95 \% \text { CI }\end{array}$ & $46.96^{*}(0.53)$ & $\begin{array}{c}-0.88^{*}(0.14) \\
{[-1.47,-0.29]}\end{array}$ & $-0.07^{*}(0.02)$ & $-0.09(0.12)$ & $0.11^{*}(0.03)$ & $64.92^{*}(5.66)$ & $0.09(0.07)$ & $0.27(0.51)$ & $18.15^{*}(1.34)$ & .227 \\
\hline \multicolumn{11}{|c|}{$\begin{array}{l}\text { Physical: Maximum } \\
\text { walking distance }\end{array}$} \\
\hline $\begin{array}{l}\text { Age } \\
\quad 95 \% \mathrm{CI}\end{array}$ & $50.02^{*}(0.59)$ & $\begin{array}{r}-0.99^{*}(0.09) \\
{[-1.54,-0.44]}\end{array}$ & $-0.04^{*}(0.01)$ & $0.42^{*}(0.10)$ & $0.03^{*}(0.01)$ & $48.70^{*}(5.00)$ & $0.08(0.05)$ & $0.47(0.31)$ & $29.88^{*}(1.66)$ & .311 \\
\hline $\begin{array}{l}\text { Mortality } \\
95 \% \text { CI }\end{array}$ & $44.67^{*}(0.57)$ & $\begin{array}{r}-1.70^{*}(0.15) \\
{[-2.77,-0.63]}\end{array}$ & $-0.06^{*}(0.02)$ & $0.02(0.13)$ & $-0.00(0.03)$ & $69.79^{*}(6.38)$ & $0.30^{*}(0.12)$ & $2.83^{*}(0.80)$ & $26.43^{*}(1.65)$ & .347 \\
\hline \multicolumn{11}{|l|}{$\begin{array}{l}\text { Health: Body mass } \\
\text { index }\end{array}$} \\
\hline $\begin{array}{l}\text { Age } \\
\quad 95 \% \mathrm{CI}\end{array}$ & $48.33^{*}(0.51)$ & $\begin{array}{c}-0.12^{*}(0.08) \\
{[-0.74,0.50]}\end{array}$ & $-0.04^{*}(0.01)$ & $-0.10^{*}(0.09)$ & $0.05^{*}(0.01)$ & $39.95^{*}(4.10)$ & $0.10^{*}(0.05)$ & $-0.44(0.29)$ & $13.09^{*}(0.85)$ & .071 \\
\hline $\begin{array}{l}\text { Mortality } \\
95 \% \text { CI }\end{array}$ & $48.41^{*}(0.67)$ & $\begin{array}{c}-0.43^{*}(0.19) \\
{[-1.70,0.84]}\end{array}$ & $-0.02(0.01)$ & $-0.15(0.16)$ & $0.01(0.04)$ & $48.27^{*}(4.30)$ & $0.42^{*}(0.14)$ & $1.65^{*}(0.62)$ & $11.81^{*}(0.89)$ & .162 \\
\hline \multicolumn{11}{|l|}{$\begin{array}{l}\text { Social: Social } \\
\text { participation }\end{array}$} \\
\hline $\begin{array}{l}\text { Age } \\
\quad 95 \% \mathrm{CI}\end{array}$ & $50.03^{*}(0.55)$ & $\begin{array}{r}-0.82^{*}(0.11) \\
{[-1.50,-0.14]}\end{array}$ & $-0.03(0.02)$ & $0.20(0.11)$ & $0.02(0.02)$ & $38.77^{*}(5.17)$ & $0.12^{*}(0.07)$ & $0.61^{*}(0.31)$ & $23.25^{*}(2.35)$ & .287 \\
\hline $\begin{array}{l}\text { Mortality } \\
95 \% \mathrm{CI}\end{array}$ & $44.20^{*}(0.62)$ & $\begin{array}{r}-1.65^{*}(0.20) \\
{[-1.65,-1.65]}\end{array}$ & $-0.01(0.04)$ & $-0.44^{*}(0.21)$ & $-0.08(0.05)$ & $59.06^{*}(7.40)$ & $0.00(0.19)$ & $1.53(1.11)$ & $24.51^{*}(2.89)$ & .249 \\
\hline \multicolumn{11}{|l|}{$\begin{array}{l}\text { Self: Emotional } \\
\text { balance }\end{array}$} \\
\hline $\begin{array}{l}\text { Age } \\
\quad 95 \% \text { CI }\end{array}$ & $49.71^{*}(0.66)$ & $\begin{array}{c}-0.07(0.11) \\
{[-0.59,0.45]}\end{array}$ & $-0.03^{*}(0.01)$ & $-0.09(0.11)$ & $0.03(0.02)$ & $66.54^{*}(6.92)$ & $0.07(0.07)$ & $0.52(0.30)$ & $26.72^{*}(2.38)$ & .064 \\
\hline $\begin{array}{c}\text { Mortality } \\
95 \% \text { CI }\end{array}$ & $49.13^{*}(0.63)$ & $\begin{array}{l}-0.42^{*}(0.18) \\
{[-1.13,0.29]}\end{array}$ & $-0.05^{*}(0.02)$ & $-0.00(0.14)$ & $0.05(0.03)$ & $83.99^{*}(8.35)$ & $0.13(0.12)$ & $0.62(0.21)$ & $26.26^{*}(2.54)$ & .081 \\
\hline
\end{tabular}

Note. Ns range between 420 (Body mass index) and 439 (Social participation) who provided between 678 (social participation) and 1,090 observations (Categories). $\Delta$ Pseudo- $R^{2}$ was calculated as proportional reduction in residual variance from unconditional means model. Unstandardized estimates and standard errors are presented. Level 2 indicates the extent of the association between differences in intercept and within-person rates of change and Time 1 (T1) age or time-to-death. 95\% CI (confidence intervals) indicate range of between-person differences in rates of change in brackets. Categories $=$ index of crystallized abilities (fluency); participants were asked to name as many animals as possible in $90 \mathrm{~s}$; Hearing = measured separately for each ear using a Bosch ST-20-1 pure-tone audiometer with headphones; scores represent an inverted average of thresholds in dB across both ears and four frequencies $(1.00,2.00,4.00$, and $6.00 \mathrm{kHz})$. Maximum walking distance = index of lower body function; measured by self-report on a scale ranging from 0 (not being able to walk) to 7 (being able to walk five kilometers or more); Body mass index $=$ calculated from height and weight of the participants as $\mathrm{kg} / \mathrm{m}^{2} ;$ Social participation $=$ unit weight composite across social activities reported in the semistructured Yesterday Interview (e.g., attending cultural events, visiting people) and an Activity List (e.g., restaurant visits, dancing, volunteer work, playing games; see Lövdén et al., 2005); Emotional balance = based on composites generated across 10 items of positive affect (e.g., enthusiastic, excited, proud) and 10 items of negative items (e.g., distressed, afraid, upset) of the Positive and Negative Affect Schedule (Watson et al., 1988); scores were calculated as positive affect - negative affect. T-scores were standardized to cross-sectional Berlin Aging Sample Studysample at T1 $(N=516, M=50, S D=10)$. In the age models, intercepts are centered at age 85 . In the mortality models, intercepts are centered at 2 years prior to death. Ttd $=$ Time-to death. ${ }^{*} p<.05$

Received December 19, 2010

Revision received October 5, 2012

Accepted October 16, 2012 